\title{
III. Der Quellenbestand
}

\section{1. "Mandements", "quittances", "comptes", »inventaires" - das archivalische Material}

Die Einheitlichkeit des zugrunde liegenden Überlieferungskörpers ist nicht so sehr durch die Art der einzelnen Quellen gekennzeichnet, als dadurch, daß die in die Untersuchung aufgenommenen Belege jeweils explizit notieren, daß dieser oder jener Gegenstand direkt als étrennes deklariert ${ }^{l}$ oder als bestimmt für den (premier) jour de l'an bezeichnet worden ist. Dies gilt nicht nur für die Archivalien $^{2}$, sondern auch für die wenigen historiographischen und literarischen Zeugnisse. So sind all jene Quellenbelege in die Untersuchung aufgenommen worden, die einen eindeutigen Hinweis auf eine Verbindung zwischen Gegenstand und Schenkdatum ${ }^{3}$ liefern und die einzelne Gabe damit zum Neujahrsgeschenk machen, eben erworben oder erhalten als étrennes, zum premier jour de l'an, zum premier jour de janvier oder zum jour de l'an. Durchgängig gilt: immer waren es Personen, die zum neuen Jahr beschenkt wurden, nie irgendwelche wie auch immer gearteten »Körperschaften ${ }^{4}$.

Der weitaus größte Teil der verwendeten archivalischen Belege entstammt den Beständen der Bibliothèque Nationale de France und den Archives Nationales und ist dort durchgesehen worden, so auch die in Paris auf Mikrofilm vorhandenen burgundischen Rechnungsüberlieferungen beziehungsweise Teile der 》Collection de Bourgogne « 5 . Archivalien des Hauses Orléans konnten

1 Bzw. in den entspr. Schreibweisen wie estrinnes, estrain(n)es usw.

2 Zur methodischen Reflexion über und Anleitung für den Umgang mit Archivalien äußerst hilfreich sind, obschon aus volkskundlicher Sicht, die Aufsätze von Karl-Sigismund KRAMER zur historisch-archivalischen Methode: KRAMER 1968 und KRAMER 1983.

3 Siehe auch oben S. 51, Anm. 70.

4 So traten bspw. Städte, siehe unten S. 77 mit Anm. 25, nicht in den Geschenkverkehr zum neuen Jahr ein. - Anders verhält es sich selbstverständlich mit verschiedenen Schenkgruppen wie den Sekretären des Herzogs von Berry, die mehrmals für Neujahrsgeschenke für ihren Herrn »zusammenlegten“, siehe Anhang - Katalog/Jahreslisten, Nr. 1283, 1337, 1359,1468 und 1660, oder den dames und damoiselles d'honneur am Hof der Königin, zu diesen nun MÜNSTER 2000.

5 Einen quellenkundlichen Überblick über Rechnungen als fiskalische und sozial-ökonomische Dokumente geben CAENEGHEM, GANSHOF 1963, S. 97-106. Neueren Datums, aber enttäuschend unvollständig ist BUCHHOLZ 1996 zur »Geschichte der öffentlichen Finanzen in Europa in Spätmittelalter und Neuzeit«. Rechnungen als historische Quellen behandelt mit umfassender Bibl. die Seite »computatio« im Internet unter der Adresse »http://onlinemedia.uni-marburg.de/ma_geschichte/computatio« von Otto VOLK, Harm von SEGGERN u.a. Aktuell und grundlegend zu spätmittelalterlichen Rechnungen MERSIOWSKY 2000 am Beispiel der territorialen Rechnungslegung im deutschen Nordwesten, hier S. 19-22 zur Überlieferung territorialer Rechnungen im europäischen Mittelalter, S. 19f. zu Frankreich. - Einschlägige Hilfsmittel: Allg.: MOLINIER, Des origines aux guerres d'Italie, Bd. 4, 1904 (hier 
nicht am Ort überprüft werden, da sich diese heute in London befinden ${ }^{6}$. $\mathrm{Zu}$ dem müssen, was die Vollständigkeit des vorhandenen und was die Vollständigkeit des vorgelegten Materials anbelangt, einige einschränkende Bemerkungen vorausgeschickt werden.

Zum ersten ist die einschlägige, den höfischen Geschenkverkehr der Zeit Karls VI. von 1380 bis 1422 betreffende archivalische Überlieferung, die sich in der Hauptsache auf die Herzöge von Burgund, Orléans und Berry sowie die Mitglieder der Königsfamilie selbst konzentriert, mit Ausnahme Burgunds nicht vollständig. Die bekanntesten EEreignisse und Umstände, die in Paris lagernde Bestände dezimierten oder derart verstreuten, daß eine vollständige Durchsicht nur mit erheblichem zusätzlichem Zeit- und Kostenaufwand durchzuführen gewesen wäre, waren der Brand der Chambre des comptes 1737, die

zu Karl VI. S. 117ff., Nr. 3571-3815); STEIN 1907; Chartes et diplômes relatifs à l'histoire de France, 1908ff.; LAUER, Collections manuscrites, 2 Bde., 1905-1911. - Avignon: BAUTIER, SORNAY, Les sources de l'histoire économique et sociale, Bd. 1,2, 1971. - Brüssel: Inventaire des archives des chambres des comptes, hg. von PINCHART, NELIS, 6 Bde., 1837-1931; PINCHART 1879; PIOT 1879. - Burgund: BAUTIER, SORNAY, Les sources de l'histoire économique et sociale, Bd. 2,1/2, 1984 (Artois und Flandern, Brabant). Einen Überblick über die burgundische Rechnungsüberlieferung gibt PARAVICINI 1996, siehe hier auch S. 48-54 die tabellarische Übersicht über die erhaltenen Rechnungen der recette générale des finances 1387-1477. - Dijon: Archives Départementales de la Côte d'Or, 5 Bde., 1863-1878. - Lille: Archives Départementales du Nord, 8 Bde., 1899-1895; Archives Départementales du Nord, 2 Bde., 1921 (Répertoire numérique). - Orléans: Archives Départementales de Loiret, 1976. - Paris, Nationalarchiv: Les Archives Nationales. État Général des Fonds: L'Ancien Régime, 1978; PARAVICINI 1980; REY-COURTEL 1985. Paris, Nationalbibliothek: Catalogue des manuscrits français. Anciens petits fonds, 5 Bde., 1868-1902; DELISLE, Inventaire général, 2 Bde., 1876-1878; DELISLE, Les Collections de Bastard d'Estang à la Bibliothèque Nationale, 1886; Catalogue général des manuscrits français, 9 Bde., 1899-1918; Catalogue des manuscrits français. Nouvelles acquisitions françaises, 4 Bde., 1899-1918; LAUER, Catalogue des manuscrits de la Collection Clairambault, 3 Bde., 1923-1932; PARAVICINI 1981. - Zur "Collection de Bourgogne«, die sich im Kern der Transskriptionsleistung von in Dijon liegenden Archivalien des Dom Urbain PLANCHË und seinen Mitarbeitern verdankt (siehe zur »méthode historique mauriste» am Beispiel der Collection de Bourgogne AUGER 1987), der sich auf diesem Weg die Grundlage für seine Geschichte Burgunds schuf (PLANCHER, MERLE, Histoire générale et particulière de Bourgogne, 4 Bde., 1739-1781, vgl. VAUGHAN 1975, S. 35), PETIT 1896 und LAUER, Collections manuscrites, Bd. 1, 1905, S. 1-60; vgl. „État sommaire de la collection de Bourgogne«, in: BEC 22 (1871) S. 238-241. Siehe PARAVICINI 1981, S. 53.

6 Es handelt sich v.a. um die Sammlung des Baron Gaulle de JOURSANVAULT, die 1838 versteigert worden ist, und sich heute zum größten Teil in London befindet, vgl. PARAVICINI 1981, S. 66, siehe zum Bestand: Catalogue analytique des archives de M. le Baron de Joursanvault, 2 Bde., 1838, und Archives Départementales de Loiret, 1976. - London selbst aufzusuchen, war nicht möglich. Herrn Claus Frömsdorf, Syndicus der Kieler Universität, sei an dieser Stelle für die Bewilligung einer finanziellen Unterstützung zum Erwerb von Kopien herzlich gedankt. 
Französische Revolution und ihre Kriege ${ }^{7}$ und der gelehrte Sammeleifer des 18. und 19. Jahrhunderts.

Es gibt zweitens so gut wie keine eigene Rechnungsüberlieferung von den in der höfischen Hierarchie nachgeordneten Personen selbst, die es ermöglicht hätte, das Gesamtbild abzurunden ${ }^{8}$. Beeinträchtigt wird dieses Gesamtbild zusätzlich dadurch, daß in den Quellen nur im günstigsten Fall beide Seiten des jeweiligen Gabentausches notiert sind (deren Existenz allerdings nur unterstellt werden kann).

Drittens schließlich wurde anfangs der Anspruch verfolgt, einen großen Vergleich in Zeit und Raum zu ziehen, der dazu führte, mit der Sichtung des erhaltenen Rechnungsbestandes im Pariser Nationalarchiv zu beginnen, so daß am Ende des befristeten Forschungsaufenthalts nicht mehr die Zeit blieb, die Überlieferung der Kernzeit 1380 bis 1422 so umfassend, wie es wünschenswert gewesen wäre, zu bearbeiten. Was diese Zeit betrifft, war allerdings aufgrund des Umfangs des tatsächlich verarbeiteten Quellenbestandes von weiteren Belegen lediglich eine Bestätigung der festgestellten Ergebnisse zu erwarten, keine die unten beschriebenen Gesamttendenzen ad absurdum führenden Angaben ${ }^{9}$. Wie bereits oben im Vorwort erwähnt, wurde diese Erwartungshaltung durch spätere Stichproben auch tatsächlich nicht widerlegt. Das bedeutet aber auch, daß die durchgesehene Überlieferung wesentlich umfangreicher ist, als es das im Anhang gegebene Quellenverzeichnis anzeigt.

Tabelle 1 gibt einen Überblick über die für die vorliegende Arbeit genutzte archivalische Überlieferung und veranschaulicht damit auch Überlieferungslücken, allerdings nicht danach unterschieden, ob diese nun tatsächlich existieren oder aus vorgenannten Gründen nicht verarbeitet werden konnten. Die Tabelle gibt eine zahlenmäßige Übersicht über die im Anhang in den Jahreslisten aufgeführten Quellenzitate nach Provenienz und Zuordnung ohne Einbezug von Belegen, die ausschließlich der Literatur oder Editionen entnommen worden sind. Deutlich wird das Übergewicht der burgundischen Überlieferung, wobei allerdings berücksichtigt werden muß, daß diese Überlieferung auch zahlreiche Schenkvorgänge belegt, die nicht ausschließlich burgundisch sind. Eine erneute und zum Teil neue Durchsicht der einschlägig

7 Siehe LALOU, Elisabeth: Art. "Chambre des comptes«, in: LexMA, Bd. 2, 1983, Sp. 1673-1675, hier Sp. 1675, BULST, Neithart: Art. »Finanzwesen, -verwaltung. III. Frankreich «, in: ebd., Bd. 4, 1989, Sp. 461-463, hier Sp. 461; vgl. ESCH 1985, S. 565, einen Hinweis Werner Paravicinis verwertend, zur Vernichtung von Akten am Beispiel des Pariser bureau de tirage der Revolutionszeit. Vgl. KRUSE 1996, S. 25-27, 40 mit Anm. 131 zum Brand am Beispiel der écroes mit weiteren Nachweisen.

8 Eine Ausnahme ist der 1887 ed. »Livre de comptes 1395-1406« von Guy de La Trémoille und Marie de Sully: TRÉMOILLE 1887.

9 Siehe aber auch unten S. 194, Anm. 441. 


\begin{tabular}{|c|c|c|c|c|}
\hline Jahr & Kgtm. & Burgd. & Orl. & Berry \\
\hline 1381 & & 16 & & \\
\hline 1382 & & 20 & & \\
\hline 1383 & & 34 & & \\
\hline 1384 & 4 & 24 & & \\
\hline 1385 & & 42 & & \\
\hline 1386 & & 33 & & 15 \\
\hline 1387 & 1 & 40 & & \\
\hline 1388 & 2 & 41 & & \\
\hline 1389 & 2 & 34 & & \\
\hline 1390 & 30 & 37 & 2 & \\
\hline 1391 & 43 & 29 & 4 & \\
\hline 1392 & 11 & 28 & 13 & \\
\hline 1393 & 2 & 51 & & \\
\hline 1394 & 4 & 21 & & \\
\hline 1395 & 13 & 14 & 14 & \\
\hline 1396 & & 47 & 29 & \\
\hline 1397 & 9 & 54 & 14 & \\
\hline 1398 & 2 & 84 & 46 & \\
\hline 1399 & 1 & 9 & 2 & \\
\hline 1400 & 2 & 19 & 9 & 1 \\
\hline 1401 & 24 & 7 & 38 & 2 \\
\hline
\end{tabular}

\begin{tabular}{|c|c|c|c|c|}
\hline Jahr & Kgtm. & Burgd. & Orl. & Berry \\
\hline 1402 & 6 & 9 & 14 & 7 \\
\hline 1403 & 5 & 5 & 9 & 11 \\
\hline 1404 & & 12 & 2 & 11 \\
\hline 1405 & 4 & 1 & 1 & 16 \\
\hline 1406 & & 4 & 1 & 14 \\
\hline 1407 & & 22 & 13 & 12 \\
\hline 1408 & 1 & 9 & 1 & 16 \\
\hline 1409 & & 3 & & 8 \\
\hline 1410 & & 15 & & 17 \\
\hline 1411 & & 3 & 25 & 13 \\
\hline 1412 & 6 & 1 & 3 & 5 \\
\hline 1413 & & 21 & & 25 \\
\hline 1414 & 13 & & & 32 \\
\hline 1415 & & & 4 & 27 \\
\hline 1416 & & & & 10 \\
\hline 1417 & & 13 & & \\
\hline 1418 & & 1 & & \\
\hline 1419 & & 41 & & \\
\hline 1420 & & 5 & & \\
\hline 1421 & & 4 & & \\
\hline 1422 & & & & \\
\hline
\end{tabular}

Tab. 1: Archivalische Überlieferung und Überlieferungslücken 1381-1422

relevanten Quellenbestände ${ }^{10}$ wird im übrigen zeigen, daß die bislang gewonnenen Ergebnisse aufgrund der Überlieferungslage nicht nur nicht wider-

10 Hier eine Liste der Bestände, die mit Blick auf den Zeitraum 1380 bis 1422 im Rahmen einer künftig durchzuführenden Revision erneut systematisch durchgesehen werden könnten: ACO: B 1474 ( ${ }^{\text {er }}$ Compte de Jean d'Auxonne, receveur général des duché et comté de Bourgogne, 1388-1389), B 1475 ( $3^{\mathrm{e}}$ compte de Pierre du Celier, receveur général de toutes les finances, 1389), B 1499 ( $1^{\text {er }}$ compte de Joceran Frepier, receveur général des duché et comté de Bourgogne, 1394-1395), B 1502 ( ${ }^{\mathrm{C}}$ compte de Joceran Frepier, receveur général des duché et comté de Bourgogne, 1395-1396), B 1507 ( ${ }^{\mathrm{e}}$ compte de Joceran Frepier, receveur général des duché et comté de Bourgogne, 1396-1397), B $1463^{\text {bis }}\left(1^{\text {er }}\right.$ compte de Jean des Pouillettes, receveur général de toutes les finances, 1397-1398), B 1513 (4 compte de Joceran Frepier, receveur général des duché et comté de Bourgogne, 1397-1398), B 1515 ( $5^{\mathrm{e}}$ compte de Joceran Frepier, receveur général des duché et comté de Bourgogne, 13981399), B 1518 ( $6^{\mathrm{e}}$ compte de Joceran Frepier, receveur général des duché et comté de Bourgogne, 1399-1400), B 1523 (Compte de Robert Balleure, maître de la Chambre aux deniers, 1400-1401), B 1527 (Compte de Jacques Balleure, maitre de la Chambre aux deniers, 1402), B 1551 (Compte de Jean Sarrote, commis payer les dépenses du Comte de Charollais et de Mesdemoselles de Bourgogne, ses sæurs, 1407-1408), B 1568 (Compte de Jean Vélery, maître de la Chambre aux deniers, 1411-1412), B 1576 (4 $4^{\circ}$ compte de Jean de Noident, receveur général de toutes les finances, 1413-1414), B 1578 (Compte de Jean Vélery, maitre de la Chambre aux deniers, 1412-1414), B 1581 (Compte de Jean Vélery, maître de la Chambre aux deniers, 1414-1415), B 1588 ( $1^{\text {er }}$ compte de Jean Fraignot, receveur général des duché et comté de Bourgogne, 1415-1417), B 1589 (Compte de Jean Vélery, maître de la Chambre aux deniers, 1415-1418), B 1593 (Compte de Pierre Gorremont, receveur général de toutes les finances du Roi de France, 1417-1418). - ADN: B 1894 ( $1^{\text {er }}$ compte de Robert de Bailleux, receveur général des finances, 1411-1412), 
legt werden, sondern daß das Übergewicht der burgundischen Überlieferung noch stärker zutage treten wird, konnte doch die das Königshaus, Orléans oder Berry betreffende Überlieferung relativ vollständig berücksichtigt werden.

Von einer »époque des étrennes « zu sprechen im Sinn eines besonderen Zeitraums, mithin im Sinn des deutschen Begriffs »Epoche«, währenddessen allein in Paris etwa sechshundert Goldschmiede beschäftigt waren ${ }^{11}$, könnten schon allein die festgestellte Quantität und vor allem auch die Qualität des höfischen Geschenkverkehrs zum neuen Jahr der Zeit um 1400 nahelegen. Philippe Henwood, der den Begriff »époque» freilich in einer anderen Bedeutung verwendet hat und sich schlicht auf die (Jahres)Zeit bezieht ${ }^{12}$, hat

B 1903 (Compte de Pierre Macé, commis de par monseigneur le duc de Bourgogne à la recepte de toutes ses finances, 1414-1415), B 1920 ( ${ }^{\text {er }}$ compte de Guy Guilbaut, receveur général de toutes les finances, 1419-1420), B 1925 ( $3^{\mathrm{e}}$ compte de Guy Guilbaut, receveur général de toutes les finances, 1421-1422), B 1927 ( $4^{e}$ compte de Guy Guilbaut, receveur général de toutes les finances, 1422-1423). - AN: K 500 (Inventaire des joyaux, meubles et livres des ducs d'Orléans, 1404), K 532-537 (Dons sur les ducs d'Orléans, 1400-1499). BNF: 26006-26096 (Quittances et pièces divers. 26006-26025: Charles V, 26026-26054: Charles VI, 26055-26096: Charles VII). - Eine im Sinn einer überprüfenden Revision durchgefuihrte systematische Durchsicht fand statt bei den folgenden Archivbeständen: ACO: B 1457, B 3157, B 1461, B 1463, B 1462, B 1465, B 1466, B 1467, B 1469, B 1471, B 1476, B $1479^{1}$, B $1479^{2}$, B 1481 , B 338, B 1486, B 1487 , B 1493, B 1495, B 1500 , B 1501 , B 1503, B 1508 , B 1511, B 1514, B 5518, B 1517, B 1519, B 5519, B 1526, B 1532, B 1538, B 5520, В 301 , В 302, В 1543, В 1547, В 1554, В 1556, В 1558, В 1560, В 1570 , В 1572, В 1594, B 1598, B 1601, B 1603, B 1606. - ADN: B 1863, B 1878, B 1897, B 1923. - AN: J 645, pièce 55. - BNF: Collection de Bourgogne.

11 Siehe HENWOOD 1982, S. 86. HENWOOD 1980, S. 203 mit Anm. 1 und 2 berichtet nach den "Remontrances de l'université et de la ville de Paris à Charles VI«, ed. Henri MORANVILLÉ, in: BEC 51 (1890) hier S. 428, Art. 27, auch, daß es gerade die Goldschmiede waren, die Hersteller der kostbarsten Arbeiten, deren vermeintliche Habgier in den Blick des Cabochiens-Aufstands von 1413 geriet, vgl. auch HENwOOD 1996, S. 325f. Ergänzend heranzuziehen: NOCQ, Le poinçon de Paris, 5 Bde., 1926-1931.

12 Vgl. HENWOOD 1980, S. 193 und HENWOOD 1982, S. 87: "C'est la plupart du temps, auprès des orfêvres, changeurs et marchands parisiens que se fournissent les princes au moment des somptueux échanges de joyaux dont l'époque des étrennes est alors l'occasion." Vgl. DURRIEU 1904, S. 132 in Bezug auf das Januarblatt in den »Très Riches Heures«: »Or, la place dans le manuscrit de cette image du festin au mois de janvier nous reporte à l'époque des étrennes, ces étrennes que les comptes nous attestent avoir tenu une si grande place dans les relations du duc de Berry avec son entourage, et, en particulier, avec ses artistes préférés. - Siehe zu dem hier nicht anlegbaren Konzept der »longue durée« BRAUDEL 1958. Vielmehr handelt es sich bei der wépoque des étrennes«, den Begriff tatsächlich als "Epoche" übersetzt, um eine "conjuncture». - Der Reihung "temps court - conjuncture longe durée« ließe sich die von Malcolm VALE eingebrachte, an den Hofordnungen gewonnene Reihung "occasion - regulation - institution « gegenüberstellen, die dieser in seinem Vortrag $"$ Household organization in England, Northern France and the Low Countries, 1270-1384: some general observations « auf dem 5. Symposium der Residenzen-Kommission zu dem Thema »Höfe und Hofordnungen« 1997 vorgestelit hat (nicht aufgenommen in den Bd. Höfe und Hofordnungen, hg. von KRUSE, PARAVICINI, 1999). Da es sich bei dem Geschenkverkehr der étrennes aber nicht um einen schriftlich geregelten Vorgang handelt 
diesen Zeitraum aufgrund einer eingehenden Untersuchung des Schicksals der königlichen Sammlungen anhand der erhaltenen königlichen Inventare ${ }^{13}$ (es handelt sich um diejenigen von 1380, 1391, 1400 und 141314) beschrieben,

wie bei den Hofordnungen (obwohl ab 1433 auch das Schenken erfaßt wird, siehe S. 90 mit Anm. 86), auf den der Begriff »regulation « abzielt, ihm aber die Regelmäßigkeit und Dauerhaftigkeit institutionalisierten Handelns eignet, das u.a. der Aufrechterhaltung gesellschaftlicher Ordnung und der Orientierung von Handeln im Rahmen bestimmter Wertbeziehungen dient (hier mag der Hinweis auf LIPP, Wolfgang: Art. "Institution«, in: Wörterbuch der Soziologie, hg. von ENDRUWEIT, TROMMSDORF, Bd. 2. 1989, S. 306f. genügen - siehe auch unten Kap. B. I. das Konzept des Hofes als einem sozialen System, in welches Überlegungen zum Institutionenbegriff eingegangen sind), scheint die Reihung woccasion - institution - organisation« sinnvoller, legt man eine Definition von Organisation zugrunde, die diese nicht als abstrakt-eigenständiges System sieht, sondem in erster Linie als einen lebensweltlich konstituierten Handlungs- und Kommunikationszusammenhang mit einer eigenen spezifischen Kultur und eigenen Subkulturen, mit bestimmten Interaktionsregeln, Reproduktionsund Integrationsmechanismen etc. (vgl. TÜRK, Klaus: Art. »Organisationssoziologie«, in: Wörterbuch der Soziologie, hg. von ENDRUWEIT, TROMMSDORF, Bd. 3, 1989, S. 474-481, hier v.a. S. 478-480).

13 Inventare definiert als Schatzinventare. Vgl. das Kap. „Vom geistlichen und weltlichen Sinn eines Schatzes« bei FrJTZ 1982, S. 88-109, hier v.a. S. 109 die Ausführungen über den "Schatz als Mittel der Politik« mit einem Beispiel aus der burgundischen Geschichte, nach welchem Philipp der Gute einen Teil seines Schatzes zu Hilfe nahm, um seine Überzeugungsarbeit für einen Krieg gegen Utrecht zu unterstützen, vgl. Georges Chastellain, GEuvres, ed. KeRvyn DE LeTtenhove, Bd. 3, 1864, S. 92. - Vgl. BERKING 1996, S. 78 (nach BOURDIEU 1987, S. 220), wonach die »Akkumulation materieller Reichtümer, die Anhäufung von Gegenständen, die im rökonomischen Sinne ‘ nutzlos erscheinen, vor allem als Mittel [dient], symbolische Macht zu erwerben, die sich ihrerseits als >Macht zur Durchsetzung der Anerkennung von Macht` betätigt. Die ausgezeichneten Gegenstände, die der Gabentausch bewegt und die die Gemüter erregen, liefern auch und gerade deshalb einen so außerordentlichen Grund für die andauernden sozialen Kämpfe um ihren temporären Besitz, weil sie wesentlich >Instrumente der Machtdemonstration durch Vorzeigen( sind.«

14 1380: Am Anfang konnte Karl VI. 1380 den Schatz seines Vaters übernehmen, der Bestand ist notiert in einem Inventar von 1380: Inventaire du mobilier de Charles $V$, roi de France, BNF ms.fr. 2705 (eingegangen in DELISLE, Recherches sur la librairie de Charles V, 2 Bde., 1907, pass.), ed. LABARTE, Inventaire du mobilier de Charles V, 1879 (siehe auch die Ed. PRAET 1863). Etrennes sind hier allerdings nicht verzeichnet, lediglich S. XIXf. geht LABARTE kurz auf das "Goldene Rößl« ein (siehe oben S. 62, Anm. 133). - 1391: BNF ms.fr. 21445; aufgelistet sind Eingänge 1391-1398, vgl. HENWOOD 1980, S. 185, siehe Anhang - Katalog/Jahreslisten, Nr. 552, 608, 648f., 656f., 661f., 664f., 673 und 675. - 1400: BNF ms.fr. 21446; aufgelistet sind Eingänge bis 1405, vgl. HENWOOD 1980, S. 196, siehe Anhang - Katalog/Jahreslisten, Nr. 547, 552, 614, 661, 665, 674f., 793, 899, 931, 1025 , 1222, 1341 (das »Goldene Rößl«) und 1345. - 1413: Ed. PANNIER 1873, siehe hier S. $211 \mathrm{ff}$. Einen Monat nach dem Tod Ludwigs von Guyenne ließen die Königin und der Herzog von Berry ein Inventar anfertigen, um durch den Verkauf der joyaux den Krieg mit England finanzieren zu können (vgl. HENWOOD 1980, S. 209f.), allerdings ohne Hinweise auf étrennes, siehe oben S. 61 und unten S. 78, Anm. 33. - Weitere königliche Inventare der Zeit Karls VI., die ebenfalls nur spärliche Hinweise auf étrennes liefern: AN J 645 (État des joyaux données à la reine Isabelle, lors de son arrivée en Angleterre, et réclamés par la France en l'année 1400, ed. DOUËT D'ARCQ, Choix des pièces inédites, Bd. 2, 1864, S. 273279; siehe auch: Chronique De La Traison Et Mort De Richart Deux Roy Dengleterre; ed. 
mit verschiedenen früheren Inventaren verglichen ${ }^{15}$, und in drei Phasen eingeteilt 16 .

Die Zeit von 1380 bis 1400 sei gekennzeichnet gewesen von einer »équilibre précaire ${ }^{17}$. So sei der große Bestand, den Karl V. seinem Sohn hinterlassen hatte, zwar einerseits erheblich dezimiert worden, zunächst durch Ludwig I. von Anjou, der noch am Tag der Weihe seines Neffen die Hand auf den Schatz seines Bruders legte ${ }^{18}$, dann durch die Freigebigkeit Karls VI. selbst ${ }^{19}$. Verschwendung als das negative Pendant der Freigebigkeit klar benennend und mit einem nicht zu übersehenden Seufzer zwischen den Zeilen bemerkte der Mönch von Saint-Denis ${ }^{20}$ : le roi, dans sa prodigalité sans

WILliaMS [zur Chronik unten S. 142, Anm. 27], S. 108-113 zum Inventar der Juwelen von Isabella), AN KK 39 (Charles VI: Inventaire des joyaux du roi, 1418, ed. DOUËT D'ARCQ, Choix des pièces inédites, Bd. 2, 1864, S. 279-361; vgl. VALLET DE VIRIVILLE 1857), AN KK 54 (Inventaire des tapisseries de Charles VI, vendues ou dispersées par les Anglais de 1422 à 1435, ed. GUIFFREY 1887), BNF ms.fr. 9430 (Inventoire des livres du roy Charles [VI] [...] estans en sa librairie du Louvre, 1413, eingegangen in: DELISLE, Recherches sur la librairie de Charles V, 2 Bde., 1907, pass.), BNF ms.fr. 21444 (Inventaire des meubles et joyaux du roi Charles VI: Inventaire de Jacques l'Empereur, garde des joyaux après Guillaume Foucault), schließlich auch das von Louis-Claude DOUËT D'ARCQ ed. »Inventaire de la bibliothèque du Roi Charles VI, fait au Louvre en 1423, par ordre du régent duc de Bedfordж: DOUËT D'ARCQ 1867, vgl. die Ed. STRATFORD 1993.

15 Siehe HENWOOD 1980, S. 180f. - Es sind dies v.a. neben dem oben S. 75, Anm. 14 aufgeführten Inventar Karis V. (Inventaire du mobilier de Charles V, roi de France, 1380, BNF ms.fr. 2705; siehe auch BNF ms.fr. 2700, Inventaire des livres de Charles V, 1373, eingegangen in: DELISLE, Recherches sur la librairie de Charles V, 2 Bde., 1907, pass.) dasjenige Johanns des Guten (Inventaire des joyaux de Jean le Bon, 1364, AN J 947, Nr. 6, ed. BAPST 1884) und jenes Ludwigs X. von 1316 (BNF ms.fr. Clairambault 832, S. 393-469). In keinem der hier vorgestellten Inventare sind Angaben über die Neujahrsgeschenke enthalten. 16 Einen knappen Überblick über fürstliche Goldschmiedesammlungen vor dem zeitlichen Rahmen der vorliegenden Arbeit gibt GABORIT-CHOPIN 1987.

17 HENWOOD 1980, S. 182-194.

18 Siehe oben S. 25, Anm. 13. Zu den Sammlungen Karls V., Karls VI. und des Herzogs Johann von Berry im informativen Überblick HABSBURG 1997, S. 11-19.

19 Der Freigebigkeit des Königs haben seine Beamten nicht ganz erfolglos versucht, Einhalt zu gebieten, siehe die bezeichnende Stelle in der Chronique du Religieux de SaintDenys, ed. BELLAGUET, Bd. 1, 1839, S. 609 (frz. Übers., lat. Orig. S. 608): »Les principaux membres de la chambre des comptes et les officiers chargés de récompenser les services voyaient avec peine ces profusions. Ils ne refusèrent pas les récompenses promises; mais pour qu'on pût, en temps et lieu, exiger la restitution des sommes superflues, ils prirent le parti d'ajouter désormais, par précaution, sur les registres royaux, en inscrivant les noms des donataires: Il a eu trop, ou bien Soit recouvré. De leur coté, les nouveaux conseillers du roi décidèrent qu'on ne garderait plus l'or monnayé dans le trésor, et qu'on l'emploierait à fondre un cerf de la grosseur de celui qu'on voyait depuis fort-temps dans la salle du Palais. Mais comme ils ne restèrent pas long-temps chargés de la direction des affaires, ils ne purent achever que la tête de cette statue."

20 Michel Pintoin (1350-1421), Cantor und Chronist von St-Denis, siehe VERNET, André: Art. "Chronique du Religieux de St-Denis«, in: LexMA, Bd. 2, 1983 , Sp. 2033f., hier Sp. 2033 nach SAMARAN 1963. Siehe insbes. GRÉVY-PONS, ORNATO 1976 zur Frage »Qui 
bornes, comblait de ses largesses tous ceux qui le sollicitaient: ou son père eût donné cent écus, il en donnait mille; aussi avait-il entièrement épuisé le trésor roya $^{21}$. Diese Freigebigkeit fand ihren Ausdruck in einer Reihe großer Feste 22 mit der entsprechenden Vergabe großzügiger Geschenke auch zum neuen $\mathrm{Jahr}^{23}$, in den Inventaren bei Entnahme aus dem Schatz mit dem Zusatz pris par le roi gekennzeichnet ${ }^{24}$. Umgekehrt waren es aber auch ebenso großzügige Geschenke an den König, die für Zuwachs in den Schatzkammern sorgten, beispielsweise von den Städten aus Anlaß seiner entrées oder wenn er sie auf seinen Reisen besuchte ${ }^{25}$, oder eben gelegentlich der Feier des Neujahrstages ${ }^{26}$. Entnahmen und Zuwächse haben sich also während dieser ersten Phase noch annähernd im Gleichgewicht befunden.

Das habe sich in dem Zeitraum von 1400 bis 1413, der Zeit der "grands engagements ${ }^{27}$, geändert. In diese Zeit fielen neben zahlreichen Entnahmen

est l'auteur de la Chronique «. Siehe des weiteren POMMEROL, Marie-Henriette de, in: Dictionnaire des lettres françaises, 1996, S. 1250f., dann die "Michel Pintoin, sa vie, son œuvre« überschriebene Einleitung von Bernard GUENÉE zur Neuausgabe der Chronik von Saint-Denis von 1994 sowie insbes. GUENÉE 1999.

21 Chronique du Religieux de Saint-Denys, ed. Bellaguet, Bd. 1, 1839, S. 609 (frz. Übers., Orig. lat. S. 608). Vgl. den heftigen zeitgenössischen Angriff gegen die der largesse gegenübergestellte prodigalité im Kap. 234 des »songe du vieil pèlerin« des Philippe de Mézières (RICHARD, Jean: Art. »Mézières, Philippe de«, in: LexMA, Bd. 6, 1993, Sp. $592 f$. mit weiteren Nachweisen) durch die »Königin Wahrhaftigkeit«: Philippe de Mézières, Le Songe du Vieil Pèlerin, hg. von COOPLAND, Bd. 2, 1969, ed. S. 238-244, Kommentar S. 24 27. Zu Mézières BELL 1955; einen Sonderaspekt behandelt JORGA 1896; zur Bedeutung Mézières KRYNEN 1981, pass.

22 Wie beispielsweise die fete de Saint Denis am 1. Mai 1389, deren Kosten für Roben und dons de joyaux in der Argenterierechnung des Amoul Boucher vom 1. Februar 1388 bis zum 31. Juli 1389, AN KK 20, fol. 166rff., mit namentlicher Nennung der Empfänger und Empfängerinnen notiert sind (siehe auch unten S. 259ff.), oder die entrée Isabeaus im August 1389, vgl. Chronique du Religieux de Saint-Denys, ed. BellagueT, Bd. 1, 1839, S. 611-617. Vgl. die hinsichtlich der Ausgaben wichtige Liste bei REY, Les Finances Royales sous Charles VI, 1965, S. 69.

23 HENWOOD 1980, S. 190 mit Anm. 3 nennt als Beispiel drei wertvolle étrennes, in der vorliegenden Arbeit verzeichnet in Anhang - Katalog/Jahreslisten, Nr. 439, 786 und 1744.

24 HENWOOD 1980, S. 189 mit Anm. 5 (BNF ms.fr. 21447 und 23931, pass.). Vgl. VAUGHAN 1962, S. 190 explizit zu der Tatsache, daß der trésor auch die wichtige Funktion hatte, étrennes zu stiften.

25 Siehe HENWOOD 1980, S. 191f. mit Anm. 4-6 auf S. 191 und Anm. 1-13 auf S. 192. Vgl. Les relations entre princes et villes, hg. von CAUCHIES, 1993. Für den mitteleuropäischen Raum siehe FRITZ 1982, S. 83-84: „Geschenke aller Art«. Vgl. exemplarisch die entrée Karls VI. in Dijon 1390: PETIT 1885. Grundlegend zu den entrées royales françaises von 1328 bis 1515: GUENÉE, LEHOUX 1968. Einige Überlegungen bei MÉRNDOL, Théâtre et politique, 1990 .

26 Dazu HENwood 1980, S. 193f. mit Anm. 2-7 und S. 194, Anm. 1-5, in der vorliegenden Arbeit notiert in Anhang - Katalog/Jahreslisten, Nr. 552, 661, 793, 899, 931, 1025, 1222 oder 1341 (das »Goldene Rößl«).

27 HENWOOD 1980, S. 194-202. 
mises en gage 28 (Verpfändungen) und vorgeblichen, die Erkrankung des Königs ausnutzenden Diebstählen ${ }^{29}$ auch die Verpfändungen an Ludwig den Bärtigen, den Bruder der Königin, unter anderem als Kompensation für die ihm versprochene Mitgift für die Heirat mit Anna von Bourbon ${ }^{30}$, und die Verwendung von joyaux für die Niederwerfung des rebellierenden Genua ${ }^{31}$.

Das Ende der königlichen Sammlungen sei schließlich in den Jahren 1413 bis 1422 erreicht $^{32}$ worden. Der Hundertjährige Krieg trat mit der Schlacht von Azincourt im Oktober 1415 vor der Besetzung von Paris durch Heinrich V. 1420 in ein neues Stadium, verschärft durch die bürgerkriegsähnlichen Auseinandersetzungen zwischen Armagnacs und Bourguignons, und mußte finanziert werden, was durch Einschmelzen, Ausmünzen und Verkauf der wertvollen Goldschmiedearbeiten unterstützt wurde ${ }^{33}$.

Neben die königlichen Inventare treten diejenigen der Herzöge und Herzoginnen, von denen die bereits vorgestellten des Herzogs von Berry aus genannten Gründen an erster Stelle anzuführen sind ${ }^{34}$. Hinweise auf étrennes liefern allerdings neben den Berry-Inventaren im wesentlichen nur die Inventare des Hauses Burgund 35 .

So z.B. an Jean de Montagu, vgl. ebd., S. 198.

29 Siehe Chronique du Religieux de Saint-Denys, ed. Bellaguet, Bd. 3, 1841, S. 331 (frz. Übers., lat. Orig. S. 330): „Ils se plaignaient entre autres choses de la cupidité insatiable du duc d'Orléans; ils prétendaient que ce prince avait forcé à Melun le trésor royal, et qu'il en avait soustrait deux cent mille écus d'or et de joyaux de la plus grande valeur, que le roi avait naguère confiés à la garde de son maître d'hôtel, en lui faisant jurer de ne révéler ce dépôt à personne sans sa permission ou celle de l'héritier du trône, son fils aîné. Ils ajoutaient que le duc avait donné cent écus d'or au gardien de la porte Saint-Martin, pour entrer secrètement à Paris pendant la nuit avec trente de ses gens, et emporter de sa maison des sommes énormes."

30 Siehe v.a. STRAUB 1965, hier insbes. S. $185 \mathrm{ff}$. Vgl. auch VALLET DE VIRIVILLE 1857.

31 Siehe HENwOOD 1980, S. $201 \mathrm{f}$.

32 Ebd., S. 203-212. Entspr. ähnlich auch der zeitliche Rahmen bis 1415 in der profundesten Studie zu den königlichen Finanzen: REY, Les Finances Royales sous Charles VI, 1965, vgl. FAVIER 1966.

33 HENWOOD 1980, S. 203-212, vgl. oben S. 61. Siehe BNF ms.fr. 25709, Nr. 753, ed. HENWOOD 1980, S. 214f.: "Charles VI ordonne de faire fondre ses joyaux pour payer son armée «, siehe BNF ms.fr. 6747, fol. 31r-34v: lettre vom 24. November 1417 mit Liste der zu verkaufenden joyaux des Herzogs von Berry, fortges. fol. 43rff., fol. $36 \mathrm{r}-38 \mathrm{r}$ : Liste von Kleinodien des Königs zum selben Zweck vom 31. September 1417 und dto. ebd., fol. 39r41r vom 11. Januar 1417. Am Ende verzeichnete das Inventar Karls VI. nur noch 539 Posten, 120 Gegenstände waren im Lauf der Jahre verschwunden, HENwOOD 1996, S. 327.

34 Siehe oben S. 59, Anm. 110.

35 ACO B 301 (Inventaire des joyaulx et objets divers laissés par Philippe le Hardi, duc de Bourgogne, 1404) und B 302 (Inventaire des biens meubles laissés par Marguerite de Flandre, duchesse de Bourgogne, 1405), ed. DehaISNES, Documents et extraits, Bd. 2, 1886, S. 825-854, 855-920, siehe Anhang - Katalog/Jahreslisten, Nr. 1020, 1123, 1172, 1239, 1286, 1311, 1321 und 1322. - Fast keine Hinweise enthalten die Inventare Orléans' AN K 500 (Inventaire des joyaux, meubles et livres des ducs d'Orléans, 1404), AN KK 264 (Louis de France et Valentine Visconti: Inventaires des vaisselles et autres objets précieux 
Beispiel für eine Notiz in einem Inventar, hier nach einem der Inventare des Herzogs von Berry: Item, une petite croix d'or garnie de quatre camahieus aux IIII bouz, un camahieu ou milieu, de V saphirs et VIII perles pendant à une petite chaiennette d'or; et darrière a un lieu pour mettre une croix; laquelle croix ainsi garnie madame la duchesse donna à monseigneur aux estraines, le premier jour de janvier l'an mil CCCC et VIII, et est la IIf partie du If IIII ${ }^{x x}$ $X I I^{f}$ fueillet dudit livre desdiz comptes ${ }^{36}$.

Die früheste Notiz eines inventarisierten Neujahrsgeschenks, die genannt werden kann, entstammt dem Inventar der Jeanne de Bretagne von ca. 1331: Item, III hennas dorés qui furent achatés a Paris; meistre Jehan le Josne en eut I, et I sourgien qui fu avecque lui l'autre, et Jehanne Damesy eut le tiers que

des duc et duchesse, 1389-vers 1409, zum Teil ed. LABORDE, Les Ducs de Bourgogne, Bd. 3, 1851, S. 35, Nr. 5420-5423; ed. GRAVES 1926) und AN KK $268^{A}$ und KK $268^{\mathrm{B}}$ (Louis de France et Valentine Visconti: Inventaire des joyaux, vaisselle et autres objets des feus duc et duchesse, 1408-1409 - Valentine Visconti: Inventaires des joyaux, vaisselle et autres objets de la duchesse, 1389, beide ed. GRAVES 1926; hier lediglich ein Hinweis, siehe Anhang Katalog/Nicht datierbare Angaben, Nr. 18), auch nicht der spätere Katalog und das spätere Inventar Karls von Orléans AN KK 269 (Vente et délivrance des draps, livres, tapisseries et autres biens meubles, 1427-1441) und AN KK 272 (Inventaire des joyaux, 1451-1463), ebensowenig wie BL Add. Ch. 11533-11543 (Inventaires des joyaux, vaisselle et autres biens des ducs d'Orléans, 1396, de leur librairie et de leur meubles du château de Cognac, 1496; collection de pièces relatives à la Normandie et à d'autres régions, concernant en particulier les dépenses et les tapisseries du duc d'Orléans et des voyages faits par ses officiers $\left[\mathrm{XV}^{e}\right.$ siècle]. Contient aussi "Inventaire des Archives de M. le Baron Joursanvault $\mathrm{n}^{\text {os }} 1-1353$, et titres des années 1351-1396«). Einige kleinere ed. bei ROMAN 1896 (13891481, siehe z.B. BNF P.O. 2155, Nr. 309 [pInventaire des joyaux et vaisselles vendus, engagés ou fondus par ordre du duc d'Orléans pour se procurer les finances nécessaires à l'expédition qu'il projetait en Lombardie, 25. September 1403, ed. ROMAN 1896, S. 192198]). Siehe zu den Sammlungen Herzog Ludwigs neuerdings ALEXANDRE 1999. - Ebenfalls keine Hinweise auf étrennes liefern die Inventare Ludwigs von Anjou: BNF ms.fr. 11861 (Inventaire des joyaux de Louis de France, duc d'Anjou, 1364-1365), BNF ms.fr. 11862 (Inventaire des pierreries de la tres noble et tres riche couronne de Louis de France, duc d'Anjou, 1373 et 1374) und BNF n.a.fr. 6838 (Inventaire de tous les joiaus d'or garnis de pierrie et des perles sans pierrie, de la vesselle d'or à pierrerie [...] Loys, fils du roy de France, duc d'Anjou [...]), ed. LABORDE, Notice des émaux, bijoux et objets divers, Bd. 2, 1853, LABORDE, Glossaire, 1872 und MORANVILLÉ 1906 ("Inventaire de l'orfevrerie de Louis I', duc d'Anjou(). - Zum zeitlich-räumlichen Vergleich wurden exemplarisch, aber zum größten Teil ergebnislos, herangezogen SCHÖNHERR 1883, der ein Inventar der Kleinodien des Herzogs Friedrich 1439 gibt, das Inventar Philipps des Guten ca. 1420 und dasjenige Karls des Kühnen von 1453 in der Ed. LABORDE, Les Ducs de Bourgogne, Bd. 2, 1851, S. 235-278, 1-202, HOBERG 1944 zu den Inventaren des päpstlichen Schatzes in Avignon 1314-1376, KURZEL-RUNTSCHEINER 1993 zu den Inventaren der Herzogin Jacobe von Jülich-Kleve-Berg 1588-1597 und zur Bedeutung von Luxusgütern für die höfische Frau des 16. Jh.s sowie STRATFORD 1993 zum Beford-Inventar. - Zu den Handschriftensammlungen der Zeit siehe unten S. 100ff. mit den entspr. Anm.

36 AN KK 258, fol. 4r, ed. GuIfFREY, Inventaires, Bd. 1, 1894, S. 16f., Nr. 12. Siehe Anhang - Katalog/Jahreslisten, Nr. 1455. 
monseigneur li donna as estrines ${ }^{37}$. Der überhaupt früheste Eintrag, der genannt werden kann, ist allerdings einer höfischen Rechnung von 1304 zu entnehmen: Item 6 plateaus d'argent dont les estoune à laz dorez et 2 à couvercle, de $31^{m} 7^{o n}$, donnés, le jour des estrennes, à Mad la Royne, de par le Roy ${ }^{38}$.

Den Auftakt des Geschenkverkehrs zum neuen Jahr markiert nach Jules Guiffrey hingegen das Geschenk von vier gesattelten Schlachtrössern Karls V. an seinen Bruder ${ }^{39}$, den Herzog von Berry: Charles $V$ ordonne d'allouer aux comptes des généraux trésoriers à Paris sur le fait des aides la somme de sis

37 Ed. DeHAISNES, Documents et extraits, Bd. 2, 1886, S. 288 nach dem Inventaire de coupes et hanaps ayant appartenu à Jeanne de Bretagne, dame de Cassel.

38 In: FAWTIER, MAILlaRD, Comptes royaux, 3 Bde., 1953-1956, hier Bd. 2, 1954 (»Comptes particuliers et comptes spéciaux ou extraordinaires«), S. 537, Nr. 23925 aus dem Compotus domini Hugonis de Bovilla, cambellani Regis, de jocalibus Regis, auditus die veneris ante festum B. Marie Magdalene, anno domini CCCIII ${ }^{\circ}$ (n.St.) nach den $»$ Extraits de Menant«, Rouen, Bibl. municipale, ms. Leber, 8570 (Menant VIII), fol. 31 (Angaben nach ebd., Bd. 2, 1954, S. 535, Anm. 1). LABORDE, Glossaire, 1872, S. 307 nennt nach DUCANGE, Glossarium ohne weitere Angabe étrennes von 1327. - Die ersten höfischen Rechnungen, d.h. Rechnungen, die den königlichen Hofhalt betreffen, stammen aus dem Jahr 1256 (auf Wachstäfelchen, siehe LOT, FAWTIER, Histoire des institutions françaises au moyen âge, Bd. 2, 1958, S. 72, notiert auch bei LALOU, Elisabeth: Art. "Chambre aux deniers«, in: LexMA, Bd. 2, 1983, Sp. 1675-1676, hier Sp. 1676), erste Rechnungen der Domänenverwaltung von 1202 (siehe BULST, Neithart: Art. »Finanzwesen, -verwaltung. III. Frankreich«, in: LexMA, Bd. 4, 1989, Sp. 461-463, hier Sp. 461), vgl. LOT, FAWTIER 1932, S. 12. Siehe für die Zeit von 1328 bis 1364: CAZELLES, Catalogue de comptes royaux des règnes de Philippe VI et de Jean II, 1984, hier v.a. die Quellenliste S. 47-88 mit Ed.- und Archivnachweisen.

39 GUIFFREY, Inventaires, Bd. 1, 1894, S. XXXVII, vgl. ebd., S. XXI mit Anm. 3. Diese Aussage wird verstärkt durch die in die gleiche Richtung gehende Bewertung des Geschenkaustausches zwischen Ludwig von Male und Philipp dem Kühnen 1369ff. bei FREDERICQ 1875, S. 52 mit Anm. 1, vgl. VAUGHAN 1962, S. 17, der allerdings, m.E. fälschlicherweise, meint: "the annual exchange of [...] étrennes between Philip and Louis of Male cannot be cited as evidence of any especially close contact or friendship between them." - Daß Neujahrsgeschenke als Teil des höfischen Neujahrsbrauchtums zuerst im 9. Jh. nachgewiesen seien, kann einer Angabe im Brockhaus entnommen werden: Brockhaus Enzyklopädie, 19. Aufl., Bd. 15, 1991, S. 481, Stw. »Neujahr«, vgl. NELSON, Janet L.: The Lord's anointed and the Peoples choice: carolingian Royal Ritual, in: Rituals of Royalty, hg. von CANNADINE, PRICE, 1987, S. 137-180, die S. 154, 166ff. von Neujahrsgeschenken berichtet, die Karl dem Großen dargebracht worden seien (also von »unten nach oben«). LEBEUF, Recueil, Bd. 2, 1738 , S. 248-262 versucht in seiner »Remarque sur les Dons annuels faits anciennement aux Rois de France de la seconde race, ou à l'occasion des livres offerts en forme de présens, on parle de ceux qui ont été donnez depuis à la Bibliothèque de Charles $V$. et de ceux que Jean Duc de Berry son frere reçut en Etrennes au premier Janvier« einen diesbezüglichen Überblick auf der Grundlage zahlreicher Belege zu geben, siehe hier v.a. S. 252f., kommt aber zu $\operatorname{dem}$ Schluß: »Il est vrai que les siècles suivans ne fournissent point de preuves sur cette regularité des Dons annuels. On ne voit presque plus de mention de Bibliothèque du Palais ou de Bibliothèque Royale jusqu'au tems des saint Louis, \& il paroît qu'elle ne recommença à prendre son ancien lustre que sous Charles Cinquième«, siehe ebd., S. 257. 
cens frans d'or, lesquiex li nous ont fait bailler et delivrer pour paier quatre courciers, avecques quatre selles sur les diz courciers, que nous avons donnez à nostre frère le duc de Berry le jour de l'an ${ }^{40}$, notiert in einem mandement 41 vom 10. Januar 1364: Diese Notiz läßt sich durch weitere Belege der Jahre bis 1380 ergänzen, in der Hauptsache Burgund und Berry betreffend, die unten in den entsprechenden Abschnitten behandelt werden.

Das besondere Kennzeichen der überlieferten Rechnungsbelege ist ihr serieller Charakter, der es gestattet, das zu betrachtende Phänomen über einen längeren Zeitraum hindurch $\mathrm{zu}$ beobachten. Diese Belege sind unterschiedlichster Natur und folgen im Idealfall im Buchungsgang auf der Seite des Schenkers der Regel Zahlungsbefehl: mandement ${ }^{42}$ - Quittung: quittance ${ }^{43}$ - Buchung: compte 44 (- Inventarisierung auf der Gegenseite), so daß ein Geschenk theoretisch mindestens dreimal (viermal) belegt sein kann. Tatsächlich ist eine solch gute Überlieferungslage jedoch aus oben genannten Gründen $^{45}$ nicht der Fall.

Buchungstechnisch-administrativ gesehen war der Geschenkverkehr angesiedelt bei all den mit einer Rechnungslegung betrauten Institutionen und Ämtern ${ }^{46}$. In erster Linie handelte es sich dabei um die chambre aux deniers, die

40 BNF ms. fr. 20414, fol. 1, siehe Mandements et actes diverses de Charles V, ed. DELISLE 1874, S. 79, Nr. 163. - Bereits aus dem Jahr 1358 stammt eine einen ganz anderen Bereich betreffende königliche Anweisung: Ledit concierge à cause de ladite Conciergerie, peut et doit mettre au Palais et ès Allées de la Mercerie en haut et en bas audit Palais, tels Merciers ou Mercieres que bon luy semble, ou à ses Officiers, bailler Places, changer icelles et iceux, ou aucuns d'eux boutter et mettre hors de leurs Places et rappeller, et souffrir vendre iceulx en quelque Place que ce soit, toutes fois qu'il luy plaira. Et s'il advient que lesdits Merciers dudit Palais veulent faire ensemble ou chascun par foy, aucune courtoisie une fois de l'an, comme aux Estraines ou autrement, ledit concierge le peut prendre sans offense, et ainsi a esté faict de long-temps, ed. Ordonnances des Roys de France, ed. SECOUSSE, Bd. 3, 1732, S. 310-316: Lettres concernant les Privileges, Droits et prerogatives, et la jurisdiction du concierge du Palais à Paris (Charles, regent, Jean $\mathrm{I}^{\mathrm{er}}$ et selon d'autres, Jean II. au Louvre lès Paris, en Janvier 1358), hier S. 313f., Nr. 5.

41 Hier: Zahlungsanweisung. Siehe auch unten S. 87.

42 U.a. auch als lettre close oder lettre patente, dazu GIRY 1894, S. 759f. Siehe auch unten S. 87, vgl. BOÜARD 1929, S. 37, 52 (hier zum Problem der zum Teil unklaren Scheidung der lettres von den mandements).

43 Siehe JASSEMIN 1933, S. 121f. Siehe auch unten S. 87.

44 Zur Entwicklung der comptes LOT, FAWTIER, Histoire des institutions françaises au moyen âge, Bd. 2, 1958, S. 184-191, zum examen des comptes JASSEMIN 1933, S. 115-130.

45 Siehe oben S. 71.

46 Für den großen Überblick VIOLLET, Histoire des institutions, 3 Bde., 1890-1903, dann v.a. DUPONT-FERRIER, Études sur les institutions financières de la France à la fin du moyen âge, 2 Bde., 1930-1932 (hier v.a. Bd. 2: "Les finances extraordinaires et leur mécanisme() sowie DUPONT-FERRIER, Nouvelle série d'études sur les institutions financières de la France à la fin du moyen âge, 2 Bde., 1933-1936 (Bd. 3: "Les origines et le premier siècle de la Chambre ou Cour des Aides de Paris«, Bd. 4: "Les origines et le premier siècle de la Cour du Trésor«) und LOT, FAWTIER, Histoire des institutions françaises au moyen âge, Bd. 2, 
»Hofzahlmeisterei« oder $"$ Hofrechnungskammer $«{ }^{47}$. Diese Einrichtung verantwortete Ausgaben und Zahlungen des hôtel wie desjenigen des Königs/der Königin oder des Herzogs/der Herzogin ${ }^{48}$, also deren gesamter Hofhaltung, mit einem maitre de la chambre aux deniers ${ }^{49}$, einem $»$ Hofzahlmeister $«$, an der Spitze, der das Amt des maître de l'hôtel ${ }^{50}$, des »Hofmeisters «, in Personalunion innehaben konnte. In der Hofzahlmeisterei wurden die täglichen Ausgabenlisten gefuihrt, kontrolliert und summiert und am Ende eines Rechnungs(halb)jahres an die chambre des comptes ${ }^{51}$, der für die wordentlichen

1958. Von deutscher Seite der - ältere - Beitrag HOLTZMANN 1910, hier S. 253-273 zur Finanzverwaltung. Einschlägige finanzgeschichtliche Untersuchungen von REY, Les Finances Royales sous Charles VI, 1965, für König und Königin (und deren Nachwuchs), ergänzend FAMIGLIETTI 1986, für die Bretagne von KERHERVÉ, L'État breton, 2 Bde., 1987, für Burgund v.a. die Arbeiten von Andrée van Nieuwenhuysen: NIEUWENHUYSEN 1965, 1967, 1980, 1984 und zuletzt, unter ähnlichem Titel wie 1984, 1990. - Regionalstudien zu städtischen Finanzen geben u.a. CLAUZEL 1982 (Lille) und HUMBERT 1961 (Dijon).

47 Siehe zunächst LALOU, Elisabeth: Art. "Chambre aux deniers«, in: LexMA, Bd. 2, 1983, Sp. 1675-1676 mit bibl. Nachweisen. Zum Überblick LOT, FAWTIER, Histoire des institutions françaises au moyen âge, Bd. 2, 1958, S. 74f., 198-200. Ed. von Rechnungen DOUËT D'ARCQ 1865. Zur Organisation der königlichen chambre aux deniers innerhalb des königlichen hôtel REY, Les Finances Royales sous Charles VI, 1965, S. 21-99, v.a. S. 55ff. Auch die Königin verfügte über eine eigene Hofrechnungskammer, siehe ebd., S. 215-239. Zur burgundischen Hofzahlmeisterei NIEUWENHUYSEN 1990, S. 126-137. Eine Einzelstudie bietet MIROT 1938 (Johann Ohnefurcht 1398 bis 1405 nach den Rechnungen der Chambre aux deniers).

48 Zur ersten Information LALOU, Elisabeth: Art. »Hôtel du roi«, in: LexMA, Bd. 5, 1991, Sp. 140f. mit bibl. Nachweisen. Im Überblick LOT, FAWTIER, Histoire des institutions françaises au moyen âge, Bd. 2, 1958, S. 66-74, zur Organisation des königlichen Hofhalts REY, Les Finances Royales sous Charles VI, 1965, S. 23-55. Zur Frage, ob denn nun die königliche Hofverwaltung der herzoglich-burgundischen als Vorbild gedient habe oder umgekehrt zuletzt KRUSE 1996, S. 26 mit Anm. 82 und S. 39f. mit Anm. 130.

49 Siehe v.a. REY, Les Finances Royales sous Charles VI, 1965, S. 55-59, zu Isabeaus maître de la chambre aux deniers ebd., S. $200 \mathrm{f}$.

50 Zum Hofmeister knapp LALOU, Elisabeth: Art. „Maître de l'Hôtel, Grand«, in: LexMA, Bd. 6, 1993, Sp. 147, vgl. LOT, FAWTIER, Histoire des institutions françaises au moyen âge, Bd. 2, 1958, S. 66, ansonsten v.a. REY, Les Finances Royales sous Charles VI, 1965, S. 34 51, zu Isabeaus maitre de l'hôtel ebd., S. $193 \mathrm{ff}$.

51 Auch hier zunächst LALOU, Elisabeth: Art. »Chambre des comptes«, in: LexMA, Bd. 2, 1983, Sp. 1673-1675 mit bibl. Nachweisen. Älteren Datums JASSEMIN 1933, dort zusammenfassend (1357 bis 1436) S. XLII-LXVII. Aktuell und grundlegend: Les Chambres des comptes, hg. von CONTAMINE, MATTEONI, 1998. Zum Überblick LOT, FAWTIER, Histoire des institutions françaises au moyen âge, Bd. 2, 1958, S. 240-244 und, älteren Datums, HOLTZMANN 1910, S. 268-270, zu den Ursprüngen LUCHAIRE 1892, S. 590f., zum einschlägigen Kontext REY, Les Finances Royales sous Charles VI, 1965, S. 492f. und pass. Einzelstudien: Zur Brüsseler Rechnungskammer KAUCH 1945, zu derjenigen von Dijon ANDT 1924. 
Einnahmen«, also diejenigen aus der Domäne ${ }^{52}$, zuständigen Institution, als das übergeordnete Kontrollorgan mit allen Belegen weitergeleitet ${ }^{53}$.

Beispiel für eine Notiz in einer Rechnung der chambre aux deniers, hier in einer derjenigen des Herzogs von Berry ${ }^{54}$ : $A$ luy [Johann von Berry] pour bailler et paier certains marchands à Paris dont il avoit acheté certains joyaux pour donner au Roy et à plusieurs le premier jour de l'an [1371], en estrennes, 200 liv.t. 55.

Dem Hofmeisteramt waren nicht nur die einzelnen Hofämter und andere für die Hofhaltung wichtige Bereiche unterstellt wie im Falle des königlichen Hofmeisteramtes auch die Pariser Korporationen, sondern insbesondere auch die argenterie $^{56}$. Hier mußte fur all die Belange Sorge getragen werden, die das (tägliche) Leben des Herrschers direkt betrafen wie Kleidung und Wäsche, Möbel und Juwelen, Reisen und Feste ${ }^{57}$ und eben Geschenke. Das Argentiersamt, eine Einrichtung, über die neben dem Königshaus nur noch Burgund verfügte $^{58}$ (abgesehen von der Bretagne), hatte demzufolge auch die Aufsicht

52 Zu den Einkünften aus den Domänen: REY 1949 und REY, Le domaine du roi, 1965, knapp HOLTZMANN 1910, S. 255-259, zur Bedeutung apanagierter Gebiete zunächst WOOD 1966 (unter den Kapetingern), exemplarisch LACOUR 1934 zur Apanage Johanns von Berry, FAUSSEMAGNE 1937 zur mapanage ducal de Bourgogne dans ses rapports avec la monarchie française, 1363-1477 « und LEGUAI 1962 zu derjenigen der Herzöge von Bourbon.

53 Vgl. REY, Les Finances Royales sous Charles VI, 1965, S. 492ff. Kurze Schilderung dieses Ganges nach den Mémoires des Olivier de La Marche der Zeit Karls des Kühnen für den burgundischen Hofhalt bei KRUSE 1996, S. 15f. mit weiteren Nachweisen. Exemplarisch SCHWARZKOPPF 1970, v.a. aber NIEUWENHUYSEN 1990, S. 126-137. - Benutzte Rechnungen der chambre aux deniers, die étrennes verzeichnen: Burgund: ACO B 5518 (I ${ }^{\text {er }}$ Compte de Jean de Velery, maître de la Chambre aux deniers; fol. 1-9: 1. Juni 1398-31. Dezember 1398; fol. 9-112: 1. Januar 1399-31. Dezember 1400), ACO B 5519 (II Compte de Jean de Velery, maître de la Chambre aux deniers, 1. Januar 1401-31. Dezember 1402), ACO B 5520 (III $^{\circ}$ Compte de Jean de Velery, maître de la Chambre aux deniers, 1. Januar 1403-30. Juni 1405). Berry: AN KK 254 (Jean de France: Chambre aux deniers, Hôtel, 1399-1401, Forts.: BNF ms.fr. 6744). - Ed. von Rechnungen der chambre aux deniers u.a. DOUËT D'ARCQ 1865, hier ed. auszugsweise u.a. von AN KK 30: Karl VI. 1380-1390, AN KK 33: Karl VI. 1421-1422, AN KK 45: Isabeau 1398-1403, AN KK 50: Karl VII. 1421-1423, AN KK 52: Karl VII. 1450-1461, AN KK 63: Ludwig XI. 1471-1483, AN KK 253: Berry 1397-1399, BNF ms.fr. 6740: Hofausgabenrechnung Karl VI. 1388.

54 Zu den Rechnungsbeständen Berrys im Überblick oben S. 59, Anm. 110.

55 AN KK 251, fol. 19r, ed. GUIFFREY, Inventaires, Bd. 2, 1896, S. 321.

56 Zur ersten Information BAUTIER, Robert-Henri: Art. "Argenterie du roi«, in: LexMA, Bd. 1, 1980, Sp. 922-923 mit bibl. Nachweisen sowie LOT, FAWTIER, Histoire des institutions françaises au moyen âge, Bd. 2, 1958, S. 73, 269. Zur königlichen Argenterie Karls VI. insbes. REY, Les Finances Royales sous Charles VI, 1965, S. 137-172, zu derjenigen Isabeaus ebd., S. 239-272.

57 Siehe oben S. 77, Anm. 22.

58 Vgl. NIEUWENHUYSEN 1990, S. 276. 
über einige Handwerker wie die Schneider und es waren ihm die coffres ${ }^{59} \mathrm{zu}-$ geteilt. Der argentier hatte wiederum seine eigenen Rechnungen vorzulegen ${ }^{60}$.

Beispiel für eine Notiz in einer Rechnung der argenterie, hier in einer derjenigen Isabeaus de Bavière ${ }^{61}$ : Pour XXI aulnes d'escerlate que la Royne a données a monseigneur le chancelier de France et a monseigneur levesque de Noyon le premier jour de janvier aux estrainnes a chascun la moitié, au pris de CXII s.p. l'aune, valent CXVII l. XII s.p. ${ }^{62}$.

Die notwendigen Mittel für die chambre aux deniers und die argenterie stellte unter anderem die trésorerie ${ }^{63}$ zur Verfügung, die sich neben den ordentlichen Einnahmen zu einem nicht unerheblichen Teil aus Steuergeldern, den außerordentlichen Einkünften ${ }^{64}$, finanzierte, wobei die Monarchie für

59 Siehe zu den coffres royaux REY, Les Finances Royales sous Charles VI, 1965, S. $442 \mathrm{ff}$.

60 Benutzte Argentiersrechnungen, die étrennes enthalten: Burgund: ACO B 1466 (Compte de Josset de Halle, argentier du duc de Bourgogne, 1386-1387), ACO B 1471 (Compte de Josset de Halle, argentier du duc de Bourgogne, 1387-1388), ACO B 1476 (Compte de Josset de Halle, argentier du duc de Bourgogne, 1388-1390), ACO B 1481 (Compte de Josset de Halle, argentier du duc de Bourgogne, 1390), ACO B 1486 (Compte de Josset de Halle, argentier du duc de Bourgogne, 1390-1392). Königshaus: AN KK 18 (Charles VI, 1387), AN KK 19 (Charles VI, 1388), AN KK 21 (Charles VI, 1390-1391, 1393-1394), AN KK 27 (Charles VI, 1398-1401), AN KK 41 (Isabeau de Bavière, 13931400 , vgl. GiBBONS 2000), AN KK 42 (Isabeau de Bavière, 1401-1403, vgl. GiBBONS 2000), AN KK 43 (Isabeau de Bavière, 1403-1407). - Vgl. CAZELLES 1966, schriftl. Fassung eines Vortrags vom 16. Februar 1966 zur Argenterie Johanns des Guten und ihrer Rechnungen von 1351-1353 (zur Argenterierechnung AN KK 8, fol. 31-74 vgl. DOUËT D'ARCQ 1851). Siehe die Arbeiten von Louis-Claude DOUËT D'ARCQ 1851 und 1874. Exemplarische Ed. einer Argentiersrechnung, allerdings von 1475: ALBRECHT 1995.

61 Detailliert zur Argenterie Isabeaus KIMM 1969, S. 40-42, 105-110.

62 Neujahrsgeschenke der Königin 1403 an Arnaud de Corbie und Philippe de Moulins, AN KK 42, fol. 69v (10. Rechnung des Charles Poupart, 1. Februar 1401 bis 31. Januar 1402 a.St.), siehe Anhang - Katalog/Jahreslisten, Nr. 1220 und 1226.

63 Siehe LALOU, Elisabeth: Art. „Chambre du Trésor«, in: LexMA, Bd. 2, 1983, Sp. 16761677 mit bibl. Nachweisen und LALOU, Elisabeth: Art. »Trésor royal«, in: ebd., Bd. 8, 1996, Sp. 975-977. Grundlegend zum "personnel de la cour du trésor « DUPONT-FERRIER 1935 und 1936/1937, v.a. aber DUPONT-FERRIER, Études sur les institutions financières de la France à la fin du moyen âge, Bd. 4, 1936. Im Überblick LOT, FAWTIER, Histoire des institutions françaises au moyen âge, Bd. 2, 1958, S. 245-250. Zur Rolle der der chambre des comptes zuzuordnenden trésorerie REY, Les Finances Royales sous Charles VI, 1965, S. 63-68, 156f., vgl. zur Herkunft der Gelder u.a. auch VAUGHAN 1970, S. 145f. Zur cour $d u$ trésor als Kontrollorgan REY, Les Finances Royales sous Charles VI, 1965, S. 535ff.

64 Zur Erstinformation BULST, Neithart: Art. »Finanzwesen, -verwaltung. III. Frankreich«, in: LexMA, Bd. 4, 1989, Sp. 461-463, im Überblick DuBOIS 1986, S. 633-635 sowie LEMARIGNIER 1991, S. 374-381. Siehe ansonsten FAVIER 1971 und HENNEMAN 1971, für die Zeit vor 1380 VuITRY 1883. Grundsätzlich GUERY 1984, hier v.a. S. 1254-1264: "Du don à l'impôt: roi dépensier et état fiscal«. - Kurz, aber eingängig-prägnant das Wesen mittelalterlicher "Steuern« treffend BOSL 1994, vgl. LAUM 1960, S. 242-259. 
diese und vor allem für die aides 65 in der cour des aides ${ }^{66}$ eine eigene Institution besaß67.

Mit den aides pour la guerre läßt sich auch hinreichend erklären, warum ausgerechnet vor dem Hintergrund der sogenannten »Krise des späten Mittelalters ${ }^{68}$, in diesem Fall vor allem vor dem Hintergrund des Hundertjährigen Krieges (der die Begründung gab, Steuern zu erheben, obwohl Richard II. und Karl VI. einen Waffenstillstand ausgehandelt hatten, der, obgleich dieser Waffenstillstand schon 1400 obsolet war, eigentlich erst 1415 wieder zu Belastungen führte), Finanzmittel für die zahlreichen aufwendigen Repräsentationsbedürfnisse bereitstanden ${ }^{69}$.

65 Als außerordentliche Einnahmen in Form der aides pour la guerre, siehe DUPONTFERRIER, Études sur les institutions financières de la France à la fin du moyen âge, Bd. 2, 1932, S. 2-22 (ursprünglich hervorgegangen aus den seigneurialen aides aux quatre cas, später zum Teil in den tailles aufgegangen, wurden diese Abgaben erhoben für Lösegeldzahlungen, beim Ritterschlag des Herrn oder seines ältesten Sohnes, für die Ausstattung der ältesten heiratenden Tochter und für die militärische Ausrüstung des Herrn. Aus der im 13. Jh. erhobenen Kreuzzugssteuer als aides awo quatre cas entwickelten sich die direkt an den König gehenden aides royales, die taille beinhaltend, siehe ebd., S. 14. Vgl. FAVIER, Jean: Art. "Aides«, in: LexMA, Bd. 1, 1980, Sp. 234). Detailliert hinsichtlich der aides DUPONT-FERRIER, Études sur les institutions financières de la France à la fin du moyen âge, Bd. 2, 1932 und zuletzt v.a. REY, Les Finances Royales sous Charles VI, 1965, pass. (hier u.a. S. 70-72), auf den konkreten Kontext bezogen. - Neben den aides gehörten zu den außerordentlichen Einnahmen v.a. die taille (eine Kopfsteuer), die Zölle, die fouage (eine Herdsteuer) und als Salzsteuer die gabelle.

66 Siehe v.a. die Arbeiten von Emile Marie Joseph Gustave DUPONT-FERRIER zu den Ursprüngen und dem ersten Jh. der Cour des aides: DUPONT-FERRIER, Études sur les institutions financières de la France à la fin du moyen âge, Bd. 3, 1933 (hier auch zur Frage "Disait-on [...] la Cour des aides ou la Chambre des aides?«, S. 33-50) und über »Le personnel de la cour ou chambre des aides de Paris des origines à 1483 «: DUPONT-FERRIER 1931, 1932 und 1933. Siehe JASSEMIN 1933, pass. Im Überblick LOT, FAWTIER, Histoire des institutions françaises au moyen âge, Bd. 2, 1958, S. 279-284 und FAVIER, Jean: Art. "Aides, Cour des«, in: LexMA, Bd. 1, 1980, Sp. 234f. Zur chambre des aides als Kontrollorgan REY, Les Finances Royales sous Charles VI, 1965, S. 543f.

67 Vgl. auch das auf Burgund bezogene Schaubild bei NIEUWENHUYSEN 1990, S. 42.

68 Das »Tragicum argumentum de miserabili statu regni Francie« von François de Montebelluna, zum Teil ed. DELISLE, Un Pamphlet politique, 1886, S. 115f., eine zeitgenössische Klage über den schlechten Zustand des Königreiches nach der Gefangennahme Johanns des Guten durch die Engländer, mag den bewußten Beginn des krisenhaften Zustandes der Zeit markieren, siehe ebenso die Ed. VERNET, André: Le Tragicum argumentum de miserabili statu regni Francie de François de Montebelluna, in: ABSHF 1962/1963, S. 103-163, hier zitiert nach PONS 1993, S. 107, Anm. 30, vgl. ebd., S. 107-109.

69 Tabellen mit Angaben für die bspw. in die königliche Hofhaltung eingehenden Gelder bei REY, Les Finances Royales sous Charles VI, 1965, S. 71, S. 78, 105 (chambre aux deniers), 156, 258 (Argenterie Isabeau) etc. Allein für 1405 ordnete Karl VI. 1404 an, $74.000 \mathrm{fr}$. aus der Kasse der aides de la guerre an die Argenterie Isabeaus anzuweisen für plusieurs marchans, leider fehlen in dem Beleg Angaben zu Personen, Werten und Gegenständen und der Betrag ist sicher nicht allein für étrennes verwendet worden, BNF ms.fr. 20627 (= Gaignières 2898), Nr. 8. Vgl. für Burgund die Arbeiten von Barthélemy-Amédée 
"Le roi donnât beaucoup et sans cesse avec une déplorable faiblesse [...]. Une bonne partie des aides royales y passait. Le Trésor était comme une bourse toujours ouverte où les princes pouvaient puiser sans scrupule« schreibt Alfred Coville in seiner Untersuchung über den Cabochiens-Aufstand ${ }^{70}$. Bezeichnenderweise forderten die aufständischen Cabochiens in ihrer ordonnance $^{71}$ von 1413 in mehreren Artikeln auch den Mißbrauch abzustellen, der mit den aides betrieben wurde, und von dem bei weitem nicht nur die Prinzen profitierten 72 .

Auch trésorerie und cour des aides waren zur Rechnungslegung gegenüber der chambre des comptes verpflichtet ${ }^{73}$, die Finanzgeneräle der cour des aides

PocQuet du Haut-Jussé: PocQueT du Haut-Jussé 1938 und PoCQueT du HauT-Jussé, Les aides en Bourgogne, 1939. - Freilich genugten auch diese Finanzmittel nicht, siehe REY, Les Finances Royales sous Charles VI, 1965, pass. (hier auch Diagramme mit den Angaben für Einnahmen und Ausgaben v.a. der argenterie Isabeaus), insbes. S. 571-607 die zusammenfassende Analyse, inwieweit die gesamte königliche Familie an den causes d'un déficit beteiligt war. Vgl. ergänzend FAMIGLIETTI 1986 für den Zeitraum 1392 bis 1420. FREDERICQ 1875, S. 53 wertet die étrennes als ein Beispiel unter vielen für die von ihm als ruinös bezeichnete Geschenkpraxis Burgunds.

70 COVILLE 1888, S. 33.

71 Der älteste erhaltene Text nach CoviLLE, siehe ebd., S. 419, in der BNF ms.fr. 5273.

72 Hierzu COVILLE 1888, S. 235-247 (vgl. COVILLE 1891), vgl. auch REY, Les Finances Royales sous Charles VI, 1965, S. 361, FAMIGLIETTI 1986, S. 107-125 und BROWN, FAMIGLIETTI 1994, S. 34-38 mit weiteren Nachweisen; knapp SEIBT 1984, S. 212-214, im Überblick AUTRAND 1986, S. 470-500. - Vgl. die zeitgenössische Klage von Philippe de Mézières: Philippe de Mézières, Le Songe du Vieil Pèlerin, hg. von CoOPLAND, Bd. 2, 1969, Ed. S. 241-243, Komm. S. 26f.: 'Beau Filz, dist la royne au jeune Moyse couronné, sil te devroit souvenir des dons et de la despence des vaillans et preudommes roys tes ancesseurs, desquelx le demaine du roy estoit plain comme un cuf; et de leurs subgiez ne levoient nulles aides. Ilz avoient grant tresor et sans guerre, et toutesfois quant a leurs largesses et aux dons tu trouveras en la chambre des comptes que quant il venoit d'oultremer un tresvaillant chevalier, qui estoit tenu pour preux, pour une grant largesse au dit le roy li faisoit donner $c$. livres tournois, et a un escuir cinquante. Mais aujourduy, Beau Filz, a un petit homme et de nulle condicion mais qu'il ait des amis a court, ou a un varlet de chambre, tu donras legierement et mille et $i^{m}$ francsı (Literatur zu Mézières oben S. 77, Anm. 21).

73 Benutzte trésorerie-Rechnungen mit notierten étrennes: Burgund: ACO B 1487 ( $4^{\mathrm{e}}$ et dernier compte de Pierre du Celier, trésorier gouverneur et receveur général de toutes les finances, 1391-1392), ACO B 1493 (Débris d'un compte de Jean de Plaines, naguère trésorier des exploits de la gruerie de la Comté de Bourgogne 1392), ACO B 1495 ( $6^{e}$ compte de Josset de Halle, trésorier gouverneur et receveur général de toutes les finances, 1392-1393), ACO B 1500 ( $7^{\circ}$ compte de Josset de Halle, trésorier gouverneur et receveur général de toutes les finances, 1393-1394), ACO B 1501 ( $8^{\circ}$ et dernier compte de Josset de Halle, trésorier gouverneur et receveur général de toutes les finances, 1394-1395), ACO B 1503 ( $1^{\text {ex }}$ compte de Pierre de Montbertaut, trésorier gouverneur et receveur général de toutes les finances, 1395), ACO B 1508 ( $2^{\mathrm{C}}$ compte de Pierre de Montbertaut, trésorier gouverneur et receveur général de toutes les finances, 1396), ACO B 1511 ( $3^{\mathrm{e}}$ compte de Pierre de Montbertaut, trésorier gouverneur et receveur général de toutes les finances, 13961397), ACO B 1543 (Compte de Regnaudin Doriac, trésorier gouverneur des finances et receveur général de toutes les finances, $1404-1405$, und $4^{\circ}$ compte de Jean Chousat, trésorier 
allerdings nur zum letzten Abschluß der Rechnungen für die Gesamtbilanz, ohne daß dadurch eine Superiorität der chambre des comptes über die cour des aides konstituiert worden wäre, die formal gleichgestellt war.

Beispiel für eine Notiz in einer Rechnung des trésorier Pierre du Celier Philipps des Kühnen: Et a premier vallet de chambre de monseigneur de Berry qui semblablement apourta les estraines que mondit s. de Berry envoya led. jour a mondit s. $100 \mathrm{fr}^{74}$.

Zahlungsanweisungen ${ }^{75}$ konnten also hauptsächlich an diese beiden Einrichtungen ergehen, Quittungen ${ }^{76}$ entstanden demgemäß nicht nur bei den Hoflieferanten, sondern auch bei Ämtern, die von den Kassen Gelder erhielten 77 .

Beispiel für ein mandement Ludwigs von Orléans für die Bezahlung von étrennes, die die Herzogin Valentina Visconti 1392 verschenkt hatte: Loys filz du Roy de France duc de Touraine Comte de Valoiz et de Beaumont, a nostre amé varlet de chambre Jehan Poulain commis de par nous a recevoir et garder les deniers de noz finances salut. Savoir vous faisons que nous sommes tenuz a Jehan Tarenne changeur et bourgoiz de Paris en la somme de quatre

gouverneur des finances et receveur général de toutes les finances, 1405-1406), ACO B 1572 (Compte de Joceran Frepier, trésorier gouverneur des finances et receveur général de toutes les finances, 1412-1413), ADN B 1878 (Compte de Jean Chousat, trésorier gouverneur et receveur général des finances, 1405-1406). - Königshaus: AN KK 48 (Isabeau de Bavière: Trésorerie générale, 1408-1414). - Berry: AN KK 250 (Jean de France: Compte de la trésorerie du duc de Berry tenu par Macé Heron, trésorier général du Duc, 1413-1414). - Orléans: AN KK 267 (Louis de France et Valentine Visconti: Trésorerie générale, 1404-1405). - Ed. von Tresorerie-Rechnungen u.a. QUATREBARBES 1845, hier S. 135-148 ed. AN KK 246 trésorerie René d'Anjou 1461; MORANVILLÉ, Extraits de Journaux du Trésor, 1888; Les Journaux du Trésor de Philippe VI de Valois, ed. VIARD, 1899; RITTER 1912; Les Journaux du Trésor de Charles IV le Bel, ed. VIARD, 1917, und FAWTIER, Comptes du Trésor, 1930.

74 Belohnung für einen Boten 1391, ACO B 1487, fol. 89r. Siehe Anhang - Kata$\log /$ Jahreslisten, Nr. 427.

75 Vgl. REY, Les Finances Royales sous Charles VI, 1965, S. 60f. Hinsichtlich der Bezahlung von étrennes bspw. BNF ms.fr. 10431, pass., BNF ms.fr. 10432, S. 360, Nr. 1627 (mandement der Valentina Visconti vom 29. Januar 1401), BNF ms.fr. 20627 (= Gaignières 2898: Recueil de lettres des rois de France, ou autres pièces, concernant les étrennes, les dons etc., 1373-1574), BL Add. Ch. 2417 (Mandement de Charles duc d'Orléans, daté de Blois le 15 juin 1410), BL Add. Ch. 2440 (Mandement de Charles duc d'Orléans, daté de Paris le 20 mars 1414) usw., siehe Anhang - Katalog/Jahreslisten, pass.

76 Vgl. REY, Les Finances Royales sous Charles VI, 1965, S. 61. Im Buchungsgang offenbar als Beleg den écroes gleichrangig, vgl. JASSEMIN 1933, S. 121f. und KRUSE 1996, S. 15 mit Anm. 28. Étrennes verzeichnen u.a. ADN B 1863 (Quittances, 1. Februar 1398 bis 31. Januar 1399), BNF ms.fr. 10431, S. 12, Nr. 72, S. 210 f., Nr. 1183, S. 440, Nr. 2504 usw., noch durchzusehen wäre der Bestand BNF ms.fr. 26026-26054 (Charles VI, quittances et pièces divers).

77 Bspw. die Quittung des Gilles Malet, Bibliothekar Karls V., an François Chanteprime, receveur général des aides, über eine Summe von $300 \mathrm{fr}$. d'or für das Geschenk verschiedener joyaux 1377 au jour de l'an derrenier passé, BNF P.O. 1814, dossier 41918, Nr. 4. 
cens cinquante frans sept solz VI d.p. pour plusieurs parties de joyaux tant d'or comme d'argent contenuz et declairez en un rolle de parchemin, scellé du scel de nostre tres chiere et tres amee compagne la duchesse et signé de l'un de ses secretaires, lequel rolle nous vous envoyons attaché soubz nostre contre scel, et lesq. parties de joyaulx nostre dite compaigne a de nostre commandement et ordenance fait prendre et acheter dudit Tarenne pour donner aux estrainnes dernieres passees ou il lui a pleu. Se voulons et vous mandons que ladite somme de IIIf l.fr. VII s. VI d.ob. vous payez, baillez et delivrez audit Jehan Tarenne. Et par rapportant ces presentes, ledit rolle avec quittance dudit Tarenne ladite somme de IIIf l.fr. VII s. VI $d$. sera plainement alloee en vos comptes et rabatue de vostre recepte par ceulx a qui il appartiendra, sanz aucun contredit, nonobstant ordenances, mandemens ou defenses a ce contraires. Donné a Paris le III jour de fevrier l'an de grace mil CCC IIII ${ }^{a x}$ et onze. Par monseigneur le duc, H. Guingant. ${ }^{78}$.

Beispiel für eine quittance: Hennequin Poitevin roy des menestriers et Jehan de Pontoise menestrier du roy confesse avoir eu et receu de Godefroy le Fevre varlet de chambre de monseigneur le duc d'Orleans et garde des deniers de ses coffres la somme de vint escuz que ledit monseigneur le duc leur a donné pour eux et les menestriers du roy et de nos seigneurs des fleurs de liz pour les estraines du jour de l'an derrenier passé de laquelle somme de vint escuz dessus dicte lesdiz Hennequin et Jehan se teinrent pour bien contens et agrees et en quicterent ledit nostre seigneur le duc, ledit Godefroy et tous autres, quittant etc. promettant etc. obligeant etc. Fait l'an mil CCC IIII ${ }^{x x}$ dix sept le lundi IIIC jour de fevrier ${ }^{79}$.

Die Notiz ein und desselben Neujahrsgeschenks kann sich also an verschiedenen Buchungsorten zu verschiedenen Daten gleichzeitig befinden ${ }^{80}$, darüber hinaus können Neujahrsgeschenke, selbstverständlich nicht nur in den Endabrechnungen der (General)Rentmeister der chambre des comptes ${ }^{81}$,

78 BNF P.O. 2152, Nr. 148, ed. GRAVES 1913, S. 72, Nr. XXXII. Siehe Anhang - Kata$\log /$ Jahreslisten, Nr. 509.

79 BNF n.a.fr. 3639, Nr. 313, ed. GRAVES 1913, S. 154, Nr. CIV. Siehe Anhang - Kata$\log /$ Jahreslisten, Nr. 892.

80 Siehe bspw. Anhang - Katalog/Jahreslisten, Nr. 1222 das Geschenk Königin Isabeaus für König Karl VI. zum neuen Jahr 1403 nach AN KK 43, fol. 20, zur Inventarisierung siehe BNF ms.fr. 21446, fol. 20r.

81 Benutzte Rechnungsbücher, in denen Ausgaben für étrennes verzeichnet sind: Burgund: ACO B 1457 (Compte d'Amiot Arnaut, receveur général des finances, 1379-1380), ACO B 1461 (Compte d'Amiot Arnaut, receveur général des finances, 1383-1384), ACO B 1463 (Compte d'Amiot Arnaut, receveur général des finances, 1384-1385), ACO B 1462 (Compte d'Amiot Arnaut, receveur général des finances, 1385-1386), ACO B 1465 (1 $1^{\text {er }}$ compte d'Audot Douay, receveur général des duché et comté de Bourgogne, 1386-1387), ACO B 1467 ( $1^{\text {er }}$ compte de Pierre du Celier, receveur général de toutes les finances, 1387-1388), ACO B 1469 ( $2^{\mathrm{C}}$ compte de Pierre du Celier, receveur général de toutes les finances, 13881389), ACO B $1479^{1}$ ( $1^{\text {er }}$ compte de Pierre Varopel, receveur général de toutes les finances, 
verschiedenen Rubriken zugeordnet $\operatorname{sein}^{82}$, was die Recherche nicht gerade erleichterte. Entsprechend uneinheitlich ist der diesem Überlieferungskörper

1389-1390), ACO B $1479^{2}$ ( $2^{\mathrm{e}}$ et dernier compte de Pierre Varopel, receveur général de toutes les finances, 1390-1391), ACO B 1514 ( $2^{\mathrm{e}}$ compte de Jean des Pouillettes, receveur général de toutes les finances, 1398-1399), ACO B 1517 ( $3^{\mathrm{e}}$ compte de Jean des Pouillettes, receveur général de toutes les finances, 1399-1400), ACO B 1519 ( $4^{\mathrm{e}}$ compte de Jean des Pouillettes, receveur général de toutes les finances, 1400-1401), ACO B $1526\left(1^{\text {er }}\right.$ compte de Jean Chousat, receveur général de toutes les finances, 1401-1402), ACO B 1532 ( $2^{e}$ compte de Jean Chousat, receveur général de toutes les finances, 1402-1403), ACO B 1538 ( $3^{e}$ compte de Jean Chousat, receveur général de toutes les finances, 1403-1404), ACO B 1547 ( $1^{\text {er }}$ compte de Jean de Pressy, receveur général de toutes les finances, 1406-1407), ACO B 1554 ( $2^{\mathrm{e}}$ compte de Jean de Pressy, receveur général de toutes les finances, $1407-$ 1408), ACO B $1556\left(3^{\mathrm{e}}\right.$ et dernier compte de Jean de Pressy, receveur général de toutes les finances, 1408-1409), ACO B 1558 ( $1^{\text {er }}$ compte de Jean de Noident, receveur général de toutes les finances, 1409-1410), ACO B $1560\left(2^{\mathrm{e}}\right.$ compte de Jean de Noident, receveur général de toutes les finances, 1410-1411), ACO B 1570 ( $1^{\text {er }}$ compte de Robert de Bailleux, receveur général de toutes les finances, 1411-1412) ACO B 1594 ( $2^{\mathrm{e}}$ compte de Jean Fraignot, receveur général des duché et comté de Bourgogne, 1418), ACO B 1598 ( $3^{\mathrm{e}}$ compte de Jean Fraignot, receveur général des duché et comté de Bourgogne, 1419), ACO B 1601 ( $7^{e}$ compte de Jean de Noident, receveur général de toutes les finances, 1419), ACO B 1603 ( $8^{\mathrm{e}}$ et dernier compte de Jean de Noident, receveur général de toutes les finances, 1419), ACO B 1606 ( $4^{\mathrm{e}}$ compte de Jean Fraignot, receveur général des duché et comté de Bourgogne, 1420), ADN B 1897 ( $2^{\mathrm{e}}$ compte de Robert de Bailleux, receveur général des finances, 1412), ADN B 1923 ( $2^{\circ}$ compte de Guy Guilbaut, receveur général de toutes les finances, 1420-1421). - Königshaus: ACO B 1602 (Compte de Pierre Gorremont, receveur général de toutes les finances du Roi de France, 1418-1420), BNF ms.fr. 32511 (Extraits des comptes royaux, de rôles d'hommes d'armes, et d'autres documents de la Chambre des Comptes, du XIII ${ }^{\mathrm{e}}$ au XVI ${ }^{\mathrm{e}}$ siècle, par Caille du Fourny, 1217-1440). - Ed. von comptes u.a. VALLET DE VIRIVILLE 1859; DELISLE 1871 (ohne Befund); LECOY DE LA MARCHE, Extraits des comptes et mémoriaux du roi René, 1873; TRÉMOILLE 1887; AGNEL, Les comptes du roi René, 3 Bde., 1908-1910; Inventaires mobiliers, hg. von PROST, PROST, 2 Bde., 1902-1904 und 1908-1913; POCQUET DU HAUT-JUSSÉ, Le compte de Pierre de Gorremeont, 1937, und Comptes généraux de l'État Bourguignon, 5 Bde., 1965-1976 (hier ed. ACO B 1601, ACO B 1603, ADN B 1920, ACO B 1594, ACO B 1598, ACO B 1606, ADN B 4090, ADN B 4091). Nicht zugänglich waren die »Extraits des comptes de dépenses du roi Charles VI et de la reine 1407-1408, de $\mathrm{M}^{\mathrm{gt}}$ de Beaujeu et de $\mathrm{M}^{\mathrm{gr}}$ de Valois 1463$1464 \ll$, ed. GILLET 1860 , S. 192.

82 In der Argenterierechnung Guillaume Brunels, trésorier und argentier Karls VI., vom 1. Januar 1386 bis zum 30. Juni 1387, AN KK 18, stehen étrennes unter den Ausgaben für die Coffrerie, hier fol. 42v, in derjenigen Brunels vom 1. Januar 1387 bis zum 31. Juli 1388, AN KK 19, in dem Orfaveries pour le roy betitelten Abschn., hier fol. 62v. Die Argenterierechnung des Charles Poupart vom 1. Oktober 1398 bis zum 31. März 1399, AN KK 27, zählt Neujahrsgeschenke zu den Dons extraordinaires faiz par le Roy nostre sire a plusieurs seigneurs, chevaliers, escuiers, ses gens et officiers et autres estrangiez par le temps dess. $d i t$, hier fol. 17rf. Die Argenterie Isabeaus de Bavière führt étrennes je nach Beschaffenheit, so bei den Draps de laynnes, AN KK 42, fol. 11v, oder bei der Orfaverie, ebd., fol. 34rf., ihre Tresorerie wiederum bei den Dons faiz par la Royne, AN KK 48, fol. 123vf. usw. Pierre du Celier, burgundischer Generalrentmeister, nennt Neujahrsgeschenke bei den Deniers baillies pour achat et facon de joyaux, ACO B 1467, fol. 44r, dann bei den Autres deniers paiez pour plusieurs messaigeurs grosses et menues et pour menuz dons fait par monsieur et 
zuzuordnende »Editionskörper«; Hinweise auf vorhandene Editionen sind in der jeweils entsprechenden Rubrik des im Anhang dieser Arbeit gegebenen tabellarischen Katalogs verzeichnet. Weitere, von den vorgestellten Belegen verschiedene Archivalien betreffen beispielsweise die Rechnungslegung des châtelain (Burggrafen) von Beaune, Regnaut Monot, aus dessen Einnahmen Philipp der Kühne im Jahr 1381 die jährliche Zuwendung zum ersten Januar von 1.000 fr. an seine Gattin Margarete von Flandern bestritt ${ }^{83}$, oder den Brief, den dieser von seinem Bruder, dem Herzog von Berry, erhielt. Berry schrieb unter Hinweis auf das Geschenk, un saint Jacques le minor, das er zum Jahresanfang 1400 von seinem Neffen, Ludwig von Orléans, erhalten habe, daß das Geschenk Philipps ja wohl noch ausstehe, und er wünsche sich einen saint Jaques le grant ${ }^{84}$. Tatsächlich ist Philipp dieser Aufforderung nachgekommen, wie sowohl eine burgundische Rechnung als auch das Inventar des Herzogs von Berry belegen ${ }^{85}$.

Das (vorläufige) Ende des relativ ungeregelten Geschenkverkehrs, damit wohl auch desjenigen zum neuen Jahr, wie zu schließen ist, ließe sich mit der Hofordnung Philipps des Guten von Burgund von 1433 markieren, die bestimmte, daß wjede Vergabe eines Geschenkes die Anwesenheit von mindestens drei Räten voraussetzte $\aleph^{86}$ und gab damit dem Geschenkverkehr eine bestimmte administrative Verankerung. Es war den Höflingen fortan nicht mehr gestattet, den Herzog mehr als einmal im Jahr um ein Geschenk anzugehen; sollte versehentlich zweimal ein Geschenk vergeben worden sein, so war das Personal der Rechnungskammern angewiesen, das zweite Geschenk zurückzufordern ${ }^{87}$. Die noch im zeitlichen Horizont des späten Mittelalters

madame en maniere qui sensuit, ACO B 1469, fol. 44rf., Pierre Varopel bei den Dons, graces et restitutions, ACO B $1479^{2}$, fol. $141 \mathrm{r}, 152 \mathrm{v}$ und $154 \mathrm{v}$, allerdings dann regelmäßig. In der Rechnungslegung des Pierre Gorremont, Generalrentmeister Karls VI., vom 1. Januar 1419 bis zum 9. Dezember 1920, ACO B 1602, ed. POCQUET DU HAUT-JUSSÉ 1959, S. 190350 , sind étrennes entspr. in der Rubrik Autres deniers payés en acquit du roi pour vaisselle et joyaux, fol. 160vff., notiert.

83 Siehe Anhang - Katalog/Jahreslisten, Nr. 3.

84 Ed. bei CARTELLIERI 1910, S. 151f., Nr. XVI, dort S. 152 die Herkunftsangabe $»$ Nord B 309, Trésor des Chartes nr. 19907, III $^{e}$ Registre aux lettres Missives, fol. 216 «. Das Stück ADN B 309 ist in Archives Départementales du Nord, Bd. 1,1, 1899, S. 233 charakterisiert als »Fragment d'une lettre adressée au duc de Bourgogne par un personnage le qualifiant de très-cher et très-amé frère, au sujet des affaires de France et d'Angleterre«. Siehe Anhang Katalog/Jahreslisten, Nr. 1023 und 1034.

85 ACO B 338 und BNF ms.fr. 11496, fol. 9v, ed. GUIFFREY, Inventaires, Bd. 2, 1896, S. 15, Nr. 46 und S. $460 f$.

86 Hier zitiert nach KRUSE, Holger: Die Hofordnungen Herzog Philipps des Guten von Burgund, in: Höfe und Hofordnungen, hg. von KRUSE, PARAVICINI, 1999, S. 156, hier im Abschn. über "Gagen, Pensionen, Geschenke - finanzielle Leistungen an Amtsträger.« Die Ed. der entspr. Bestimmung findet sich bei PARAVICINI 1987, S. $215 f$., $§ 450$.

87 Siehe die Angaben oben Anm. 86 - Angaben über Neujahrsgeschenke Philipps des Guten nach 1422 bspw. bei LABORDE, Les Ducs de Bourgogne, Bd. 1, 1849, S. 264f., 
faßbaren Überlieferungen zeigen bereits Anzeichen einer Entfunktionalisierung der Neujahrsgeschenke hinsichtlich ihrer symbolischen Gehalte, ihrer jeweils auch hierarchisch begründbaren eindeutigen Zuordnungsfähigkeit oder ihrer Symptomatik sozialer Bindefähigkeit im Kräftefeld der verschiedenen Gruppierungen ${ }^{88}$, so beispielsweise nach den gleichförmigen Angaben im Compte de Pierre de Janoillac [...] pour les estrennes ${ }^{89}$ (1452-1454) Karls VII., auch wenn sie weiterhin von fürstlich instrumentalisierter Großzügigkeit zeugen ${ }^{90}$. Nur René d'Anjou scheint noch ein der Tradition eines Herzogs von Berry ebenbürtiges Schenkbewußtsein gehabt zu haben ${ }^{91}$.

\section{2. »Bon jour, bon an« - literarische und historiographische Zeugnisse}

Die Antwort auf die Frage, inwieweit und ob sich der höfische Geschenkverkehr zum neuen Jahr um 1400 in der zeitgenössischen Geschichtsschreibung und literarischen Produktion abgebildet hat, fällt wider Erwarten enttäu-

Nr. 932 (1431), S. 322f., Nr. 1081, S. 323, Nr. 1082f., S. 324, Nr. 1087-1091, S. 330, Nr. 1110 f. (alle 1432) und ebd., Bd. 2, 1851, S. 216, Nr. 4018 (1453), für den Grafen von Charolais Karl den Kühnen 1457 in einer Rechnung des Roland Pippe, receveur général, ADN B 3661, fol. 9r-10r - freundlicher Hinweis von Holger Kruse, Kiel.

88 Bestätigend KENDALl 1971, S. 74: Karl VII. schenkte seinem Sohn, dem späteren Ludwig XI., 1449 trotz Zerwürfnis ein Neujahrsgeschenk und Ludwig entledigte sich eilends des Anspruchs (»dispatched «), seinem Vater ebenfalls eines zukommen zu lassen - freundlicher Hinweis von Holger Kruse, Kiel.

89 Nun sogar als eigenes Rechnungsbuch: BNF ms.fr. 10371, vgl. BEAUCOURT, Histoire de Charles VII, Bd. 5, 1890, S. 79-82. - Vgl. auch die anderen Neujahrstermine, zu denen Karl VII. Geschenke machte oder erhielt: 1423 an seine serviteurs, siehe ebd., Bd. 2, 1882, S. 634 mit weiteren Nachweisen und 1447 an Marie de Belleville und Jeanne Rochelle, damoiselles der Königin, vgl. Mathieu d'Escouchy, Chronique, ed. BEAUCOURT, Bd. 3, 1864 , S. 259, 264. 1451 erhielt Karl vom Bischof von Bazas, Bernard du Rosier, einen traité über "Miranda in laudibus Franciæ« (erhalten in der BNF ms.lat. 6020, fol. 1-12), siehe BEAUCOURT, Histoire de Charles VII, Bd. 6, 1891, S. 406f. 1460 erhielten die Comtesse von Dunois und die Comtesse von Sancerre 412 1. 10 s.t. bzw. 550 1.t., BNF ms.fr. 20627 (= Gaignières 2898), Nr. 10. Weitere Belege bspw. AN KK 51, fol. 141ff. (1454/1455) und fol. $118 \mathrm{v}-122 \mathrm{v}(1458 / 1459)$.

90 Immerhin ließ Karl VII. durch seinen trésorier général 14.7771 .10 s. 5 d.t. anweisen pour distribuer, BNF ms.fr. 20627 (= Gaignières 2898), Nr. 9.

91 Teilw. und in Auszügen ed. Rechnungen des Herzogs (Paris: AN KK 246 Trésorerie générale, 1461; AN KK 247 Chambre aux deniers, hôtel; AN P 1334 Titres de la maison d'Anjou) bei QUATREBARBES 1845 (hier S. 135-148: AN KK 246), LECOY DE LA MARCHE, Extraits des comptes et mémoriaux du roi René, 1873 (AN P 1334) und AGNEL, Les comptes du roi René, 3 Bde., 1908-1910 (Rechnungsbestände aus den Archives départementales des Bouches-du-Rhône); zum Herzog und seinem Hof GARETS 1980; ROBIN 1985; MÉRINDOL, Le roi René, 1987, und MÉRINDOL 1993. 
schend aus, und so wundert es auch nicht, daß sich die Geschichtsforschung dieses Themas bislang noch nicht angenommen hat ${ }^{92}$.

Von den Historiographen berichtet lediglich Enguerrand de Monstrelet in Kapitel 59 von Buch I seiner »Chronique « ${ }^{93}$ zur Illustrierung der Freigebigkeit Johanns Ohnefurcht von der Vergabe von étrennes, in diesem Fall der niveaux de maçon 1410, an tous ses chevaliers et les nobles de son hostel: Et lendemain, qui fut le jour de ladicte Circunsicion [! ${ }^{94}$, du matin, le duc de Bourgongne, qui tout seul avoit plus de princes, de chevaliers et de gentilz hommes que tous les autres, donna cedit jour largement; et donna plus de joiaulx tout seul que tous les autres princes estans ce jour à Paris. Lesquelz joiaulx on a acoustumé à les donner cedit jour. Et les donna à tous ses chevaliers et les nobles de son hostel. Lesquelz dons et joiaulx, selon l'estimation de commune voix et renommée, montoient bien à la somme de quatorze mille florins d'or. Et lesdiz dons estoient en certaine significacion, car ilz estoient en semblance de ligne ou d'une rigle qu'on appelle nivel de maçon, tant d'or comme d'argent doré, et à chascun bout de chascun nyvel pendoit à une chaynète d'or ou dorée, la semblance d'un pommet d'or. Laquelle chose estoit en significacion, comme on pouroit croire et penser, que ce qui estoit fait par aspre et indirecte voie, seroit aplanyé et mis à son reigle, et le feroit mectre et mectroit à droicte ligne 95 .

Der Chronist Monstrelet, zwischen 1390 und 1400 geboren, aus dem Ponthieu und adliger Abstammung, war zunächst in Diensten des Hauses Luxemburg, ab etwa 1432 échevin im Bistum, dann in der Stadt Cambrai, wurde 1444 deren prévôt und hatte dieses Amt bis zu seinem Tod am 20. Juli 1453 inne ${ }^{96}$. Seine aus zwei Büchern bestehende Chronik hat Monstrelet wohl aus

92 Freilich ist es nicht von der Hand zu weisen, daß bei der zeitintensiven Durchsicht der Chroniken dieses oder jenes übersehen worden sein mag.

93 Benutzt in der Ed. La Chronique d'Enguerran de Monstrelet, ed. DOUËT D'ARCQ, 6 Bde., 1857-1862.

94 Vgl. die Schreibweise ACO B 302, fol. 27, ed. DEHAISNES, Documents et extraits, Bd. 2, 1886, S. 876: tableau d'ivoire a ymaiges de la Nativité et Circuncision Nostre Seigneur.

95 La Chronique d'Enguerran de Monstrelet, ed. DOUËT D'ARCQ, Bd. 2, 1858, Buch I, Kap. 59, S. 57f. Bestätigend ACO B 1558, vgl. BNF, Coll. de Bourgogne, vol. LIV, fol. 266-267v. Vgl. CHOISY 1695, 353f., PLANCHER, MERLE, Histoire générale et particulière de Bourgogne, Bd. 3, 1748, S. 303f. und HENWOOD 1982, S. 157. Hierzu Anhang Katalog/Jahreslisten, Nr. 1367, 1479 und 1484-1486 sowie 1508 mit den entspr. Anm. Zum "Krieg der Zeichen« den künftigen Druck der Baseler Diss. von Simona SLANICKA, siehe auch unten S. 193-195 mit den entspr. Anm.

96 Zu Monstrelet zunächst ViELLIARD, Françoise: Art. »Monstrelet, Enguerran(d) de«, in: LexMA, Bd. 6, 1993, Sp. 771 und der entspr. Art. von Gillette TYL-LABORY, in: Dictionnaire des lettres françaises, 1996, S. 409f. mit umfangreichen Belegen S. 410 und bibl. Angaben. Siehe auch die Arbeit von Michael ZINGEL über »Frankreich, das Reich und Burgund im Urteil der burgundischen Historiographie des 15. Jahrhunderts «: ZINGEL 1994, hier zu Monstrelet S. 38-57, zu seiner Biogr. S. 38f. mit zahlreichen Nachweisen. 
eigenem Antrieb begonnen. Er hatte sich zum einen das Ziel gesetzt, Froissart fortzusetzen und über die Kriegswirren und Zwistigkeiten unter den französischen Fürsten zu berichten, zum anderen eine praktische Unterweisung in das Waffenhandwerk zu geben und der Nachwelt ruhmreiche ritterliche Taten zu überliefern ${ }^{97}$. Allerdings unterscheide er sich, so Michael Zingel, mit seinen $» k n o c h e n t r o c k e n e n$ und langatmigen Berichten $« 98$ von Froissart grundlegend, und sein Stil erinnere an die "zahlreichen in die Chronik eingefügten Aktenstücke «99. Literarische Qualitäten interessieren hier allerdings nicht, sondern der Standpunkt seines Verfassers. Monstrelet behandelt die französisch-burgundische Geschichte der Jahre 1400 bis 1444, wobei je ein Buch zweiundzwanzig Jahre umfaßt, mit dem Tod Karls VI. als Einschnitt100. Zingel hat glaubwürdig herausgearbeitet, daß die Historiker nach der Mitte des 19. Jahrhunderts über Monstrelet den Stab zu Unrecht gebrochen haben, weil er ein proburgundischer Chronist gewesen sei, der seine Einstellung geschickt verborgen habe ${ }^{101}$. Die einzige Parteinahme Monstrelets sei offensichtlich diejenige für das Rittertum gewesen, bei wohl ehrlichem Bedauern über den Niedergang des Königreiches ${ }^{102}$. Daß Monstrelet der Verteilung der niveaux de maçon, einem antiorléanistischen Parteiabzeichen, durch Johann Ohnefurcht, dem er ansonsten sehr kritisch gegenüberstand ${ }^{103}$, solch breiten Raum gegeben hat, ist aber doch wohl eher als burgundfreundliche Position zu bewerten.

Jean Froissart ${ }^{104}$ nun nennt in seinem "Songe de Charles VI« nur das Geschenk eines Falken an Karl VI. durch den Grafen von Flandern bei der entrée Karls $1382^{105}$ in Senlis ${ }^{106}$. Ein Beispiel, in welchem die étrennes

99 Ebd.

100 Zur Chronik ebd., S. 41-43.

101 Ebd., S. 40f. Françoise VIELLIARD meint: "Seine Haltung ist gemäßigt, gleichwohl parteilich: alle seine Gewährsleute gehören der Partei der ,Bourguignons` an, « siehe VIELLIARD, Françoise: Art. »Monstrelet, Enguerran(d) de«, in: LexMA, Bd. 6, 1993, Sp. 771.

102 ZINGEL 1994, S. 41, 43f.

103 Vgl. ebd., S. 44-50, der S. 49 resümierend sogar feststellt: »Er [Monstrelet, J.H.] empfindet keine Sympyathie für Johann ohne Furcht.«

104 Zu Froissart der Art. von Gillette TYL-LABORY und Sylvie LEFĖVRE, in: Dictionnaire des lettres françaises, 1996, S. 771-776, hier zur Biogr. S. 771, zu den »Chroniques« S. 771f., bibl. Angaben zum Werk S. 775, bibl. Nachweise S. 775f., und HoEGE, Dirk: Art. „Froissart, Jean«, in: LexMA, Bd. 4, 1989, Sp. 984f.

105 Am 13. Juli 1382 nach PETIT 1893, S. 14.

106 Siehe Jean Froissart, Guvres, ed. KERVYN DE LeTTENHOVE, Bd. 10, S. 68-71, mit Anm. auf S. 461. 
offensichtlich eine etwas andere Bedeutung hatten und der Begriff hier auf die Tatsache abzuzielen scheint, daß etwas zum ersten Mal geschieht ${ }^{107}$.

Zeitlich mit dem an anderer Stelle beschriebenen Auftakt des Geschenkverkehrs zum neuen Jahr am Hof zusammenfallend ${ }^{108}$ wird in der "Chronique du Bon Duc Loys de Bourbon «109 die Gründung des Ordens vom goldenen Schild zum Neujahrstag 1367 in Moulins aus Anlaß der Rückkehr des Herzogs aus englischer Gefangenschaft erzählt: Comment le duc de Bourbon donna à plusieurs chevaliers son ordre de l'Escu d'or, le jour de l'an [.... ${ }^{110}$. Die Ritter trugen auf der Brust einen goldenen Schild, auf dem sich ein Schrägbalken aus Perlen mit dem Wort allen befand: [...] la veille du jour de l'an fut le duc Loys en sa ville de Molins, et sa chevalerie après lui; et se lougea en la dicte ville en l'hostel d'ung de ses bourgois appellé Huguenin Chauveau, qui estoit grant procureur de Bourbonnois. Et le jour de l'an, bien matin, se leva le gentil duc, pour recueillir ses chevaliers et gentils hommes, pour aller à l'esglise Nostre Dame de Molins. Et avant que le duc partist de sa chambre, les voulut estrener d'une belle ordre qu'il avoit faite, qui s'appeloit l'escu d'or. Et en celui escu d'or estoit une bande de perles ou il avoit escript: $A L L E N^{111}$.

Kapitel IV, Comment le duc de Bourbon expousa la significance de l'escu d'or aux chevaliers [...], berichtet von dem weiteren feierlichen Verlauf: Pour la solempnité du jour de l'an, après la messe solempnelle, se assist le duc à table, et fut grant le disner et plain de joie de la noble chevalerie et escuierie, qui la estoit. Et après disner, graces dites à Dieu, prononça le duc Loys de Bourbon à ses barons et chevaliers l'ordre de l'escu d'or, lequel avoit ung bel chappel vert en sa teste et dit: "Mes seigneurs, je vous remercie trestous de mon ordre que avez prinse, après ma venue d'Angleterre. Si vous vueil dire que l'ordre signifie et porte: La dite ordre signifie que tous noble qui l'ont et

107 Und dies ist ja auch die weitere abgeleitete Bedeutung von étrennes (dann aber im Sing. verwendet).

108 Siehe oben S. 80.

109 BNF ms. fr. 5064, benutzt in der Ed. Chronique du Bon Duc Loys de Bourbon, ed. CHAZAUD, 1876 (ROCHEFORT 1735, S. 32ff. ergänzt mit Hinweis auf diese Chronik mit allerdings falscher Jahresangabe die Angaben von SECOUSSE, vgl. Ordonnances des Roys de France, ed. SECOUSSE, Bd. 3, 1732, S. 313f., Nr. 5, siehe auch oben S. 52, Anm. 71). Zur Chronik der Art. über Jean d'Orville, dem Verfasser, von Françoise VIELLIARD, in: Dictionnaire des lettres françaises, 1996, S. 1490. Die Chronik ist erst 1429 im Auftrag Karls I., des Grafen von Clermont und Enkel Ludwigs II. von Bourbon, nach den Erinnerungen des Jean de Chateaumorand, eines Waffengefährten Ludwigs, geschrieben worden.

110 Chronique du Bon Duc Loys de Bourbon, ed. CHAZAUD, 1876, S. 8-12.

111 Ebd., S. 9f. Vgl. Galbreath, JÉQUIER 1978, S. 209, siehe ebd. die Abb. 598 auf S. 208 (hierzu S. 216, Anm. 24 zur Herkunft der Abb., aber leider ohne weitere Literaturangaben zum Orden). Vgl. AUTRAND 1986, S. 195f. und v.a. BOULTON 1987, S. 271-275, Abb. S. 277, Nr. 9.1. 
qui la portent doivent estre tous comme frères, et vivre et morir l'ung avec l'autre en tous leurs besoings [...] «112.

Philipp der Kühne hat später den Neujahrstag 1403 genutzt, um mit Hilfe einer in der Forschung noch nicht hinreichend geklärten Ordensgründung, die offensichtlich auch nur über burgundische Rechnungen überliefert ist ${ }^{113}$, über die am 23. Dezember 1403 endende Vormundschaft über den bis dahin minderjährigen bretonischen Herzog Johann V. hinaus Einfluß auf die Bretagne zu behalten ${ }^{14}$. Der Orden wird von Joseph Calmette als Arbre d'Or bezeichnet und sei eine Art Vorwegnahme des Ordens vom Goldenen Vlies gewesen - erschrocken über die Gesamtsumme habe Philipp aber sein eigenes Abzeichen wieder zurückgegeben und damit sei diese Ordensgründung auch wieder erledigt gewesen 115 .

Ebenfalls in den Kontext höfischen Geschenkverkehrs zum neuen Jahr ließe sich die Begegnung des französischen Königs mit Kaiser Karl IV. Anfang 1378 einbeziehen, berichtet unter anderem in der "Chronique des règnes de Jean II. et de Charles V«116. Die am ersten Januar dem Kaiser zur Begrüßung entgegengeschickte Eskorte wurde angeführt von Philipp dem Kühnen, begleitet vom Herzog von Berry, dem Grafen von Harcourt und dem Erzbischof von Sens. Der Burgunder überreichte Karl IV. une belle épée [...], ayant un pommeau et une garde d'or garnie de pierreries ${ }^{117}$. Das Herrschertreffen muß Philipp recht teuer zu stehen gekommen sein, denn seine anderen Neujahrsgeschenke dieses Jahres fielen vergleichsweise bescheiden aus ${ }^{118}$. Eine

112 Chronique du Bon Duc Loys de Bourbon, ed. CHAZAUD, 1876, S. 12.

113 ACO B 1532, fol. 254v-255r, ACO B 1538, fol. 161r.

114 Vgl. POCQUET DU HAUT-JuSSÉ 1933, S. 197 und DAVId 1947, S. 150ff. Bemerkenswert ist bei diesem Vorgang der durch die Verleihung von Kollanen konstituierten Ordensgründung die Tatsache, daß auch Schließen à l'ordre an weibliche Empfängerinnen verschenkt worden sind. Siehe Anhang - Katalog/Jahreslisten, Nr. 1242-1244, 1246-1248, 1251f., $1254,1256,1258-1260,1262 \mathrm{f} ., 1267-1272,1274,1276 \mathrm{f}$.

115 Vgl. Calmette 1996, S. 73. Boulton 1987, S. 360, Anm. 8 gibt leider keinen wieteren Aufschluß.

116 Chronique des règnes de Jean II et de Charles V, ed. DELACHENAL, Bd. 2, 1916, hier S. 200-273. Vgl. DELACHENAL, Histoire de Charles V, Bd. 5, 1931, S. 61-119 und PETIT 1909, S. 327f. Siehe zur Chronik selbst den Art. über die „Grandes Chroniques de France« von Gillette TYL-LABORY, in: Dictionnaire des lettres françaises, 1996, S. 296-298, hier S. 297. Verf. der Chronik war wohl Pierre d'Orgemont, Bischof von Thérouanne, der Sohn des französischen Kanzlers. Dies ist einer der ganz wenigen Staatsakte, die mit dem Neujahrstag in irgendeiner Verbindung stehen, der als »Termin mittelalterlicher Staatsakte« (vgl. SCHALLER 1974) selbst aber keine Tradition begründen konnte.

117 Siehe Inventaires mobiliers, hg. von PROST, PROST, Bd. 2, 1908-1913, S. 16, Nr. 97 und ebd., S. 20, Nr. 117. Vgl. BNF, Coll. de Bourgogne, vol. LXV (Extr. des Comptes généraux), fol. 30r nach PETIT 1888, S. 506. Siehe auch BNF, Coll. de Bourgogne, vol. XXVI, fol. 299 und vol. LV, fol. 50.

118 Prominentestes Geschenk war ein chapel, den die Herzogin ihrem Vater nach Flandern sandte, ACO B 1452, fol. 74. Vgl. Inventaires mobiliers, hg. von PROST, PROST, Bd. 2, 1908-1913, S. 12f., Anm. 6: »L'on a pas trouvé d'autre trace des sestrainnes` données par le 
Illumination in den »Grandes Chroniques de France « zeigt die kurz nach dem Neujahrstag erfolgte Darbietung von Geschenken durch Karl V.119 an Karl IV.

All die anderen historiographischen Quellen der Zeit berichten nichts über den Neujahrstag oder über den an diesem Tag stattfindenden Austausch von Geschenken. Möglicherweise waren die regelmäßig wiederkehrenden Festlichkeiten am ersten Januar zu unspektakulär, als daß darüber berichtet worden wäre. Immerhin gab es andere Gelegenheiten wie die entrées oder Hochzeiten, höfische Prachtentfaltung zu bestaunen, gab es andere Themen, die die Zeitgenossen bewegten, wie die kriegerischen Auseinandersetzungen mit England oder diejenigen zwischen den Bürgerkriegsparteien, gab es Ereignisse, die, weil weit dramatischer, das Denken bestimmten, wie die Morde an den Herzögen von Orléans und Burgund oder die Krankheit des Königs.

Außer Christine de Pisan und Eustache Deschamps hat sich auch die Literatur der Zeit mit und in keinem ihrer Werke (vorrangig) mit dem jour de l'an befaßt. Obwohl gerade die Gedichte, die diese beiden hinterlassen haben ${ }^{120}$, zu den materiellen Überresten des Neujahrsgeschenkverkehrs zu zählen sind, sollen sie an dieser Stelle aufgeführt werden. Dies wird damit begründet, daß sie nicht zu den überlieferten Gegenständen als Überreste im materiellen Sinn gezählt werden. Deutlich wird diese Unterscheidung bei den im folgenden $\mathrm{Ab}$ schnitt vorzustellenden Handschriften, die als étrennes verschenkt wurden. Diese teilweise überaus prächtigen Bände sprechen im Gegensatz zu den Gedichten mit (fast) keiner ihrer Zeilen den Neujahrstag an, werden aber durch ihre Funktion als Geschenk durch den Termin mit diesem verbunden und belegen dann vorrangig als gegenständliches Geschenk, nicht durch ihren Inhalt, den Gabentausch zum neuen Jahr.

Christine de Pisan, eine der wichtigsten Frauen der mittelalterlichen Literaturgeschichte, stammte aus Venedig und gelangte durch ihren Vater, der als Astrologe in den Dienst Karls V. trat, nach Paris. Verheiratet war sie mit Etienne du Castel, Notar und Sekretär am Hof. Schon 1390 verwitwet, war sie gezwungen, den Lebensunterhalt für sich und ihre Familie allein zu verdienen und tat dies dadurch, daß sie mit dem Schreiben begann. Zu ihren Gönnern gehörten neben anderen die Königin Isabeau und die Herzöge von Burgund und Berry ${ }^{121}$.

duc et la duchesse. Les cadeaux furent, peut-être, cette année-là moins nombreux considérables que de coutume, par suite des grandes dépenses qu'occasionna la venue de l'empereur Charles IV..

119 Siehe die für den Umschlag des vorliegenden Buches gewählte Abb., Grandes Chroniques de France, BNF ms. fr. 2813, fol. 478v.

120 Siehe auch oben S. 51, Anm. 67.

121 Zur Biogr. zunächst der Art, von Gillette TYL-LABORY, in: Dictionnaire des lettres françaises, 1996, S. 280-287, hier pass., bibl. Nachweise S. 287, und BRIESEMEISTER, Dietrich: Art. »Ch. de Pisan«, in: LexMA, Bd. 2, 1983, Sp. 1918f;; zur literaturgeschichtlichen 
Einerseits kann Christine de Pisan durchaus als selbständige Denkerin bezeichnet werden, wie beispielsweise ihr Verhalten im Streit um den Rosenroman zeigt ${ }^{122}$ (und sie wurde deshalb auch von manchen zur ersten Feministin stilisiert ${ }^{123}$ ), andererseits aber war sie abhängig vom Mäzenatentum der höfischen Gesellschaft. Zum neuen Jahr widmete sie ihre Balladen ${ }^{124}$ Charles d'Albret ${ }^{125}$, der Königin Isabeau ${ }^{126}$, Ludwig von Orléans ${ }^{127}$ und Marie de Berry ${ }^{128}$. Leider ist kein einziges dieser Gedichte zeitlich genau zu bestimmen, nicht einmal der Charles d'Albret verehrte »Débat de deux Amans «: Bon jour, bon an et quanqu'il puet souffire/De bien, d'onneur et de parfaitte joye,/Mon redoubté seigneur, d'Alebret sire,/Charles poissant, pri Dieu qu'il vous envoie/Ce jour de l'an qui maint bon cuer resjoie,/Et vous present/Cestui

Einordnung ZIMMERMANN 1991, hier v.a. S. 79f., 81, 83f. und zur Lyrik S. 92 sowie: Euvres poétiques de Christine de Pisan, ed. RoY, 3 Bde., 1886-1896.

$122 \mathrm{Vgl}$. ZiMMERMANN 1991, S. 79f. - Ed. des Rosenromans durch Eugène LANGLOIS, zitiert als: Guillaume de Lorris, Jean de Meung, Le roman de la rose, ed. LANGLOIS, 5 Bde., 1914-1924. Ed. mit dt. Übers. OTT, Der Rosenroman, 3 Bde., 1976-1979. Vgl. den Art. "Roman de la rose«, in: Dictionnaire des lettres françaises, 1996, S. 1308-1310 von Jean ChÂTILloN. Zu Jean de Meung und Guillaume de Lorris die Art. von Sylvie LEFĖVRE, in: Dictionnaire des lettres françaises, 1996, S. 817-819, 629f. Ed. der Texte dieser Diskussion: Le Débat sur le Roman de la Rose, hg. von HICKS, 1977, zur Erstinformation der Art. »Roman de la rose (débat sur le)« von Sylvie LEFÈVRE, in: Dictionnaire des lettres francaises, 1996, S. 1310-1312 mit editorischen und bibl. Nachweisen.

123 Vgl. RIGAUD 1911, vgl. die Beiträge in: Christine de Pizan and the categories of difference, hg. von DESMOND, 1998. Siehe auch KINTZINGER, Die zwei Frauen des Königs, 2000, S. 392, Anm. 54.

124 Vgl. RoY, Maurice: Notes, in: Euvres poétiques de Christine de Pisan, ed. RoY, Bd. 1, 1886, S. 304f. die Ausführungen zu den Balladen Nr. XVIII (an Isabeau), XIX (an Ludwig von Orléans) und XX (an Marie de Berry): "Ces ballades ont été adressées comme présents et souhaits de nouvelle année. Les envois de compliments et de vœux se faisaient toujours le $\mathrm{I}^{\mathrm{er}}$ janvier. Nous en trouvons la preuve dans les inventaires de la librairie du duc de Berry où nous voyons Christine de Pisan elle-même offrir certains de ses ouvrages en étrennes, le $\mathrm{l}^{\text {er }}$ janvier. La première de ces ballades est envoyée à la reine Isabelle de Bavière, la seconde à Louis de France, duc d'Orléans; quant à la troisième elle a été composée à l'intention de Marie de Berry, fille du duc Jean de Berry, l'un des plus puissants protecteurs de Christine." 125 Euvres poétiques de Christine de Pisan, ed. RoY, Bd. 1, 1886, S. 225f., Nr. XVI, siehe Anhang - Katalog/Nicht datierbare Angaben, Nr. 1.

126 Guvres poétiques de Christine de Pisan, ed. RoY, Bd. 1, 1886, S. 227f., Nr. XVIII, siehe Anhang - Katalog/Nicht datierbare Angaben, Nr. 3. Vgl. zum Kontext v.a. STRAUB 1981, hier insbes. S. 137f. mit Anm. 13, der diese Ballade auf 1400-1405 datiert. Vgl. KIMM 1969, S. 288, die nach: Euvres poétiques de Christine de Pisan, ed. RoY, Bd. 1, 1886, S. 248 eine weitere Ballade anfuihrt, ebenfalls undatiert, in welcher Christine die Übersendung eines gelehrten Werkes (welches?) ankündigt: Ma redoubtée, ou tout le monde encline,/Pour ce que sçay que, comme bien aprise,/Livrez amez, moy vostre serve indigne/Vous envois cestui ou est comprise/Matiere qu'ay en haulte place prise.

127 Euvres poétiques de Christine de Pisan, ed. RoY, Bd. 1, 1886, S. 228f., Nr. XIX, siehe Anhang - Katalog/Nicht datierbare Angaben, Nr. 4.

128 Euvres poétiques de Christine de Pisan, ed. RoY, Bd. 1, 1886, S. 229f., Nr. XX, siehe Anhang - Katalog/Nicht datierbare Angaben, Nr. 5. - Vgl. SOLENTE 1924, 270 mit Anm. 5. 
livret, que j'ay fait par entente,/Ou est escript et la joye et la peine/Qu'ont ceulz qu'Amours met d'amer en la sente,Si le vueilliez recepvoir pour estreine. - Et s'il vous plaist a l'ouïr ou le lire,/De deux Amans orrez qu'Amours maistroie/Si a entr'eulx debat; car l'un veult dire/Qu'Amours griefve trop plus qu'elle n'esjoie,/L'autre dit non et que plus bien envoie,/Et a l'atente/De jugement, lequel a mendre entente/Se soubzmettent et a sentence pleine;/C'est nouvel cas a journée presente,/Si le vueilliez recepvoir pour estreine. - Et non obstant qu'ayent voulu eslire/Mon seigneur d'Orliens que leur fait voie/Et juge en soit, ne vueilliez escondire/Leur bon desir, car chascun d'eulx vous proye/Trés humblement, s'il vous plaist toutevoie,/Et se guermente/Que vous dissiez vostre avis: se dolente/Vie est qu'amer ou trés joieuse et saine,/Et le livret le fait vous represente,/Si le vueilliez recepvoir pour estreine. - Mon redoubté seigneur, des meilleurs trente/Me reçoivent a vo bonté haultaine,/Cui mon service ottroy sanz estre lente,/Si le vueilliez recepvoir pour estreine ${ }^{129}$.

Eustache Deschamps ${ }^{130}$, geboren etwa 1340 , war neben Karl von Orléans und François Villon einer der bedeutendsten französischen Dichter des späten Mittelalters ${ }^{131}$. Nach einer Ausbildung in Reims und dem Studium der freien Künste an der Universität von Orléans entstand um 1360 eines seiner ersten Werke, »Geta et Amphitrion«. Ab ca. 1367 stand Deschamps in königlichen Diensten, zunächst als Bote, wodurch er Italien, Böhmen, Mähren und Flandern kennenlernte. In den 1370er Jahren trafen ihn mehrere Schicksalsschläge, die sein Werk entscheidend beeinflussen sollten: 1375 starb sein Gönner Philippe d'Orléans, 1376 erkrankte er an Arthritis, 1377 starb seine Frau, kurz danach sein erster Lehrer Guillaume de Machaut. Obwohl Deschamps nach dem Regierungsantritt Karls VI. noch mehrfach verschiedene Ämter bekleidete, sah er sich gezwungen, sich aus gesundheitlichen und finanziellen Gründen auf sein Gut bei Vertus zurückzuziehen. Anlässe genug also, der spätmittelalterlichen Melancholie als zeitgeistiger Grundstimmung

129 Heute Brüssel, BR ms. 11034. Daß Christine de Pisan eine Abschrift dieses Gedichtes Charles d'Albret schenkte, geht aus der am Beginn stehenden Widmung hervor, siehe Euvres poétiques de Christine de Pisan, ed. RoY, Bd. 1, 1886, S. 231 f., Nr. XXI, vgl. ebd., S. 305, siehe Anhang - Katalog/Nicht datierbare Angaben, Nr. 2.

130 Zur Biogr. zunächst Eustache Deschamps, Euvres complètes, ed. QUEUX DE SAINTHilAire, RAYNAUD, Bd. 11, 1903, S. 9-99, dann BOZZOLO, LOYAU, La cour amoureuse, Bd. 2, 1992, S. 73, Nr. 437, sowie die Art. von Sylvie LeFĖVRE und Paul ZUMTHOR, in: Dictionnaire des lettres françaises, 1996, S. 429-432, hier S. 229f., bibl. Angaben zum Werk S. 431, bibl. Nachweise S. 431f., und ViTALE-Brovarone, Alessandro: Art. "Deschamps, Eustache $\ll$, in: LexMA, Bd. 3, 1986, Sp. 719-722, veraltet: HOEPFFNER 1904. »Eustache Deschamps als Schilderer der Sitten seiner Zeit« behandelt DiCKMANN 1936, hier zum Neujahrstag als Fest S. 120 mit Anm. 4. Neueren Datums BOUDET, MILLET 1997.

131 Von Deschamps stammt die älteste französische Poetik, die "Art de dictier«, siehe Eustache Deschamps, Euvres complètes, ed. QUEUX DE SAINT-HILAIRE, RAYNAUd, Bd. 6, 1891, S. 266-292. 
poetische Formen zu verleihen ${ }^{132} .1389$ wurde er écuyer der Herzogin von Orléans und nach ihrer Vertreibung vom königlichen Hof einer ihrer eifrigsten Verteidiger ${ }^{133}$. Die folgende Ballade ist vermutlich Valentina gewidmet ${ }^{134}$ : Pour mon desir plus fort renouveller/Qui chascun jour en moy se renouvelle,/Vous vueil mon corps et ma vie ordener/A ce bon jour, ma dame donne et belle./Recevez lay ceste année nouvelle,/Et se le don n'est fait nouvellement/Par doulz octroy, vauldra mieulx ma querelle/ $A$ ce bon jour de renouvellement. - Je ne vous say d'autre chose estrener;/Mais au jour d'uy dame ne damoiselle/Ne me pourroit sanz vous confort donner,/Qui de doulçour estes la vraye estoille./Tant suy ferus d'amoureuse estincelle/Que ja guerir n'en pourray nullement/Se vo pitié ma doulour ne rapelle/A ce bon jour de renouvellement. - Or me vueillés, chiere dame, appeller,/Ainsi qu'Amour son vray amant appelle,/Amy parfait, qui ne saroit aler/Hors du chemin de sa doulce santelle,/Car de paour tout le cuer me sautelle/Se de vous n'ay grace et allegement./Grace requier, soit donc pité en elle/A ce bon jour de renouvellement. - L'ENVOY - Tresdoulce flour, humble com coulombelle/Et plus ferme que n'est le dyament,/Recevez moy, loial com turterelle,/A ce bon jour de renouvellement ${ }^{135}$.

Herzog Ludwig von Orléans wurde Deschamps' Freund und Gönner; Deschamps war dessen conseiller und maitre de l'hôtel und begleitete den Herzog 1391 in die Lombardei. An Ludwig ist die einzige im Zusammenhang mit dem Neujahrstag stehende exakt datierbare Ballade Deschamps' von 1398136 gerichtet 137: Du sens que Dieu donna a Salemon/Et du pouoir au grant roy Alixandre, $/ D$ u bien Hector, de le force Sanson,/De la loy Dieu soustenir et deffendre,/Craindre et amer, et d'umilité prandre,/Com saint Loys

132 Vgl. ZimmermanN 1991, S. 74f. Vgl. HuIzINGA 1975, S. 38, der Deschamps voller Sarkasmus implizit zu den Chronisten und Modedichtern der Höfe zählt, die ohne höhere Kultur und unfähig zur Hoffnung auf eine Wende zum Besseren nur jammerten, dessen Balladen, siehe S. 39, »eintönige, matte Variationen desselben dumpfen Themas« seien, schreibt ebd.: "Es muß doch wohl eine starke Schwermut unter den höheren Ständen geherrscht haben, daß der Adel seinen Leibdichter [Deschamps, J.H.] Klänge wie diese so oft wiederholen läßt: Toute léesse deffaut,/Tous cueurs ont prins pas aussaut/Tristesse et merencolie.«

133 Gleichzeitig ist Deschamps aber Verfasser des "Miroir de mariage«, siehe Eustache Deschamps, Euvres complètes, ed. QUEUX DE SAINT-HILAIRE, RAYNAUD, Bd. 9, 1894.

134 »Les souhaits de nouvelle année alternent sous sa plume avec le don de son cœur qu'il offre comme étrennes à sa dame [...] «, siehe ebd., Bd. 11, 1903, S. 275f., zu datieren auf den Zeitraum zwischen 1389 und 1405.

135 Ebd., Bd. 3, 1882, S. 213f., Ballade Nr. ccccXIl, siehe Anhang - Katalog/Nicht datierbare Angaben, Nr. 7.

136 Die Datierung orientiert sich an dem in der Ballade angesprochenen Alter Ludwigs von Orléans.

$137 \mathrm{Vgl}$. Eustache Deschamps, Euvres complètes, ed. QUEUX DE SAINT-HILAIRE, RAYNAUD, Bd. 11, 1903, S. 257. - Zu den übrigen Gedichten, darunter zwei rondeaux und zwei virelais, siehe Anhang - Katalog/Nicht datierbare Angaben, Nr. 8-16. 
le fist a son vivant,/Vous vueille Dieux estrener en donnant/Sa beneiçon et bonne renommée/Ce jour de l'an et de la en avant,/Tant que France soit par vous honourée. - Que vous aiez beauté comme Absalon,/Que vo pouoir puissez partout estendre,/Si qu'en tous lieus soit doubté vostre nom/Et que faciez a vous le monde rendre/Com les Romains, et a largesce enstendre/Vueillez toudis, sanz convoiter argent,/Que vous faictes tresor de noble gent;/Amez les bons, pugnissiez par espée/Les maufaicteurs; rendez droit jugement,/Tant que France soit par vous honourée - Que vous puissez vivre en vostre aage bon/De .LX. ans; toutes vertus comprandre;/Estre piteus ou il cherra pardon,/Si que de mal ne vous puist nul reprandre;/Mais oultremer puissez voz voiles tendre/Comme firent Charlemaine et Rolant,/Si c'om die: Loys le Conquerant/Es histoires, et que l'ame sauvée/Soit en la fin: j'en pri Dieu humblement, Tant que France soit par vous honourée. - L'ENVOY - Prince, donner ne vous sçay autre don;/Prenez en gré ma petite chançon/Ce jour de l'an, qui vous est presentée;/Et Dieux vous doint honeur, force et renon,/Sens et pouoir, de tous biens habandon,/Si que France soit par vous honourée 138 .

Ob Deschamps 1404 auch trésorier Ludwigs von Orléans war, danach dessen général des finances, kollidiert mit Hinweisen auf seine schwankende Haltung zwischen Burgund und Orléans und seinem Entschluß, sich dann doch Burgund anzuschließen, beziehungsweise sich 1404 aus der aktiven Politik zurückzuziehen. Deschamps starb zwischen 1405 und 1407, also noch vor Ludwigs Ermordung.

\section{3. "Manuscrits" - Handschriften als »Überreste»}

Wie oben bereits ausgeführt und begründet, hat der Neujahrsgeschenkverkehr nur wenige materielle Spuren hinterlassen ${ }^{139}$. In der Hauptsache sind außer dem »Goldenen Rößl«140 von den einstigen Neujahrsgaben nur noch Handschriften überliefert ${ }^{141}$. Ein schönes Beispiel ist der livre de Marc Pol des

138 Eustache Deschamps, Euvres complètes, ed. QUEUX DE SAINT-HiLAIRE, RAYNAUD, Bd. 2, 1880, S. 150f., Ballade Nr. CCXCIII, siehe Anhang - Katalog/Jahreslisten, Nr. 867.

139 Siehe oben S. 59-63 und die entspr. Anm.

140 Siehe oben S. $62 \mathrm{ff}$. und die entspr. Anm.

141 Grundsätzlich zu den Handschriftensammlungen der Zeit LeBEUF, Recueil, Bd. 2, 1738 , S. 248-262; BARROIS 1830 und PEIGNOT, Catalogue d'une partie des livres composant la bibliothèque des ducs de Bourgogne, 1841 (Herzöge von Burgund); BASTARD D'EsTANG 1834 (Herzog von Berry); DELISLE, Le cabinet des manuscrits de la Bibliothèque Impériale, 4 Bde., 1868-1881, Suppl. 1977; BEAUVOIR 1855 und BEAUVOIR 1860 (Herzog von Berry); VALLET DE VIRIVILLE, La Bibliothèque d'Isabeau de Bavière, 1858; DOUTREPONT 1906 (hier S. V-XLV Beschreibung der Vorläufer des burgundischen Inventars von 1420 und dieses selbst, einschlägige Literatur S. XLVI-XLVII, zum Teil Ed. S. Iff.); DELISLE, Recherches sur la librairie de Charles V, 2 Bde., 1907 (Karl V. und Karl VI.); HUGHES 1978 
Merveilles d'Asie la grant et d'Inde la majour et mineur, et des diverses regiones du monde, escript en françois, de bonne lettre de forme, très bien historié et enluminé tout au long ${ }^{142}$, den der Burgunderherzog Johann Ohnefurcht seinem Onkel, dem Herzog von Berry, 1413 schenkte ${ }^{143}$. Als Gegengabe Berrys einige Monate später, also aus dem Geschenkverkehr zum neuen Jahr herausgelöst, erhielt der Burgunder den »Mirouer historical« des Vincent de Beauvais ${ }^{144}$.

(Philipp der Kühne und Margarete von Flandern) und WINTER 1985 (Philipp der Kühne); auch MAIER 1963 (die päpstliche Bibliothek in Avignon 1411). - Neben den französischen Bibliophilen der Zeit sollten auch die anderen großen Büchersammler genannt werden wie der Herzog von Mailand Johann-Galeazzo (hierzu PELLEGRIN 1955/1969) oder König Wenzel (siehe KRASA 1971). - Zur höfischen Buchmalerei siehe u.a. AVRIL 1975 und AVRIL 1978 sowie THOMAS 1979, hier zu den "Très Riches Heures« S. 90f. (siehe auch für den knappen Überblick BIALOSTOCKI, Jan; ANZELEWSKY, Fedja; STERLING, Charles; SKUBISZEWSKI, Piotr; CREIGHTON, Gilbert: "Wand-, Tafel- und Buchmalerei«, in: BIALOSTOCKI 1972, S. 159-239). Ein hervorragendes Nachschlagewerk sowohl in terminologischer als auch in bibl. Hinsicht liefert JAKOBI 1993. Buchmalerei als Funktion höfischen Mäzenatentums wird angerissen bei ALEXANDER, J. J. G.: Painting and Manuscript Illumination for Royal Patrons in the Later Middle Ages, in: English Court Culture, hg. von SCATTERGOOD, SHERBORNE, 1983, S. 141-162, hier S. 160. - Von großem Wert die Bibl. SMEYERS 1985. Zeitlich zu früh bzw. zu spät, aber von grundlegender Bedeutung sind BUMKE, Höfische Kultur, Literatur und Gesellschaft, 2 Bde., 1979, und Literarisches Mäzenatentum, hg. von DEMS., 1982, sowie DAVIS 1983 (Bücher als Geschenke im 16. Jh.). - Ergänzend-illustrativ die Kataloge: Les manuscrits à peinture en France du XIII ${ }^{e}$ au $\mathrm{XV}^{\mathrm{e}}$ siècle (Ausstellungskatalog), 1955; La librairie de Philippe le Bon (Ausstellungskatalog), 1967; La librairie de Charles V (Ausstellungskatalog), 1968; Les plus belles pages manuscrites de l'histoire de France (Ausstellungskatalog), 1993 (hier Beispiele für Illuminationen und Faksimiles verschiedener Hss., u.a. S. 42-45: Christine de Pisan, Le Livre des fais et bonnes meurs du sage roy Charles V; S. 50-53: Jean Froissart, Chroniques; S. 62-65: Enguerrand de Monstrelet, Chronique); Les manuscrits à peintures en France 1440-1520 (Ausstellungskatalog), 1993. Siehe auch den Aufsatz PALAZZO 1997 über »Le livre dans les trésors du Moyen Age.«

142 Heute BNF ms.fr. 2810, Faksimile: Le Livre des Merveilles, ed. OMONT, 2 Bde., 1907.

143 Verzeichnet in dessen Inventar, siehe AN KK 258, fol. 165r, dazu DELISLE, Le cabinet des manuscrits de la Bibliothèque Impériale, Bd. 3, 1881, S. 186, Nr. 196 und DELISLE, Recherches sur la librairie de Charles V, Bd. 2, 1907, S. 254, Nr. 196 sowie GuIFFREY, Inventaires, Bd. 1, 1894, S. CLXXII, Nr. 49, siehe Anhang - Katalog/Jahreslisten, Nr. 1582. Zum Schicksal, mit Bibl. sowie äußerer und inhaltlicher Beschreibung Les manuscrits à peintures en France 1440-1520 (Ausstellungskatalog), 1993 - umfangreiche Rez. KöNIG, Eberhard, in: Kunstchronik 48 (1995) 603-625 -, S. 19, vgl. auch COUDERC 1927, S. 81 (Erklärung zu Tafel L: »Jean Hayton ou Hétoun offrant à Jean sans Peur ses fleurs des histoires des terres d'Orient. - Le Livre des Merveilles, par Marco Polo, etc. - ms.fr. 2810, fol. 226. - XV' siècle. Parchemin. 297 feuillets. Rel. maroquin rouge«), MEISS, French Painting in the Time of Jean de Berry: The Late Forteenth Century, Bd. 2, 1967, S. 314 und THOMAS 1979, S. 100f. GUIFFREY, Inventaires, Bd. 2, 1896, S. 270, Nr. 1005 (vgl. ebd., S. 242, Nr. 558 und ebd., Bd. 1, 1894, S. CLXXII, Nr: 49) erwähnt dieses Buch, ohne es jedoch als Neujahrsgeschenk zu identifizieren.

144 Vgl. MEISS, French Painting in the Time of Jean de Berry: The Late Forteenth Century, Bd. 2, 1967, S. 49, 291, 404, Anm. 45 (verzeichnet bei GUIFFREY, Inventaires, Bd. 2, 1896, S. 174, Nr. 972 nach AN KK 258, fol. 157v, Nr. 972). Dieses dreibändige Werk hatte Berry 
Die zum neuen Jahr verschenkten Handschriften zeigen ein weitgespanntes Interesse von Schenkern und Beschenkten. Es finden sich klassische, religiöse, philosophische und wissenschaftliche Werke darunter, teilweise korrespondierend mit der Person des jeweiligen Schenkers. Dabei ist anzumerken, daß Handschriften überhaupt, und dann zumal solche dieser terminlichen Zuordnung, den kleinsten Teil der fürstlichen Sammlungen ausmachten, die sich wiederum nicht nur aus geschenkten Gegenständen zusammensetzten. Johann von Berry wurden nach seinen Inventaren von 1401 bis 1416306 joyaux und Handschriften zum Geschenk gemacht ${ }^{145}$. Darunter befanden sich insgesamt 198 étrennes, immerhin fast $65 \%$. Bei den joyaux waren es 176 étrennes von 254 Geschenken, also etwa knapp $70 \%$, bei den Handschriften 22 von 52 , also nur gut $42 \%$ Prozent 146 .

Es war vor allem wieder Christine de Pisan, die als Schenkerin in Erscheinung trat, nicht, weil sie besonders großzügig war, sondern weil adliges Mäzenatentum ihr die Existenz sicherte ${ }^{147} .1404$ überreichte sie Philipp dem Kühnen un livre nommé le livre de la mutacion de fortune ${ }^{148}$. Die Gabe dieses Buches wird von Christine de Pisan selbst berichtet ${ }^{149}$ in ihrem

zunächst Jean de Montagu geschenkt und nach dessen Tod zurückerhalten (Bd. I und II heute Dublin, Coll. A. Ac. Beatty, ms. 75, Bd. III heute London, Brit. Mus., Add. 6416, Angaben nach MEISs, French Painting in the Time of Jean de Berry: The Late Forteenth Century, Bd. 2, 1967, S. 310). Siehe hierzu VOORBIJ 1991. Nicht zur Verfügung stand: Vincent de Beauvais - intentions et réceptions d'une cuvre encyclopédique du Moyen Age. Actes du $\mathrm{XIV}^{\mathrm{e}}$ colloque de l'Institut d'études médiévales, organisé conjointement par l'Atelier Vincent de Beauvais et. al. 17-30 avril 1988. Recueil publié sous la direction de Monique PAULMIER-FOUCART, Saint-Laurent 1990.

145 Nach GulfFreY, Inventaires, Bd. 1, 1894, S. Lvf., Anm. 1 seien es 307 Geschenke gewesen; tatsächlich können nur 306 Geschenke gezählt werden. Vgl. leicht korrigierend MEISs, French Painting in the Time of Jean de Berry: The Late Forteenth Century, Bd. 2, 1967, S. 290 und ebd., S. 290-297 zur Bibliophilie des Herzogs. Eine Auswertung der Inventare Berrys bei AUTRAND, Le Jour de l'An, 1999, vgl. AUTRAND, Jean de Berry, 2000, S. $482-484$.

146 Vgl. zur Bibliothek des Herzogs von Berry AUTRAND, Jean de Berry, 2000, S. 465-472.

$147 \mathrm{Zu}$ Christine de Pisan siehe oben S. 96-98 und die entspr. Anm. Grundsätzlich ZIMMERMANN 1991, S. 70-72: »Mäzenatentum und kulturelle Zentren«, siehe des weiteren oben S. 59, Anm. 113.

148 Siehe Anhang - Katalog/Jahreslisten, Nr. 1282 - Christine de Pisan, Le Livre de Mutacion de Fortune, ed. SOLENTE, 3 Bde., 1959-1964. Weder ist diese Hs. im Inventar Philipps, noch im Inventar Margaretes enthalten (beide ed. DEHAISNES, Documents et extraits, Bd. 2, 1886, S. 825-854, 855-920). Siehe hingegen DOUTREPONT 1906, S. 57f., Nr. 98. - Zur Bedeutung des Fortunamotivs in der Literatur der Zeit siehe ZIMMERMANN 1991, S. 74, in allg. Hinsicht STAROBINSKI 1994, S. 40ff. Fortuna, hg. von Walter HaUG und Burghart WACHINGER, Tübingen 1994, war leider nicht zugänglich.

149 Siehe Christine de Pisan, Le Livre des Fais et Bonnes Meurs du Sage Roy Charles V, ed. SOLENTE, Bd. 1, 1936, Kap. I: Cy dit quelle fut la cause et par qzel commandement ce livre fut fait: La verité est que c'est, en ce présent an de grâce mil quatre cent trois, après un mien nouveau volume, appelé De la Mutation de la Fortune, présenté, de ma part, audit très solennel prince monseigneur de Bourgogne, comme bonne étrenne, le premier jour 
Werk über den weisen König Karl ${ }^{150}$, welches sie - im Auftrag Philipps des Kühnen geschrieben - dem Burgunderherzog wegen seines Ablebens nicht mehr hat zukommen lassen können, und es daraufhin im nächsten Jahr dem Herzog von Berry schenkte ${ }^{151}$ (der im März 1404 übrigens ebenfalls ein Exemplar des "Livre de Mutacion de Fortune « erhalten hatte ${ }^{152}$ ): un livre en françoys, des Faiz et bonnes meurs du saige Roy Charles, $V^{\ell}$ roy d'icellui nom, ou il a escript au commancement du second fueillet: ses escuiers; couvert de cuir vermail empraint, à deux fermouers et clos de cuivre ${ }^{153}$ lautet der Eintrag im Inventar des Herzogs, dem in Form einer Randnotiz auch zu entnehmen ist, daß diesem Werk ein Wert von nur 201.154 zugewiesen wurde.

Auch 1410, 1413 und 1414 wurde Berry von Christine zum neuen Jahr bedacht, auch diese Handschriften sind in dessen Inventar verzeichnet, und auch sie sind uns überliefert. 1410 erhielt Berry Les Sept psaumes en françois allégorisés $^{155}$. Die Schrift enthält eine Vielzahl von Anspielungen auf die

de janvier que nous appelons le jour de l'an, lequel volume sa débonnaire douceur reçut très aimablement; [...], vgl. HUGHES 1978, S. 171, Nr. 19 und S. 181, Nr. 11.

150 Christine de Pisan, Le Livre des Fais et Bonnes Meurs du Sage Roy Charles V, ed. SOLENTE, 2 Bde., 1936-1940. Siehe La Librairie de Charles V (Ausstellungskatalog), 1968, S. 7, Nr. 1.

151 Vgl. z.B. VaughaN 1962, S. 198.

152 Vgl. GuIFFrEY, Inventaires, Bd. 1, 1894, S. CLXXVI, Nr. 70 und MEISS, French Painting in the Time of Jean de Berry: The Late Forteenth Century, Bd. 2, 1967, S. 372, Anm. 175, S. 300, S. 405, Anm. 109 und S. 310; heute Den Haag, Koninglijke Bibliotheek, ms. 78 D 42. Maurice RoY weist in: CEuvres poétiques de Christine de Pisan, ed. ROY, Bd. 1, 1886, $\mathrm{S}$. X mit Anm. 1 ein Exemplar der Bibliothèque Nationale de France als ms.fr. $607 \mathrm{zu}$.

153 Inventareintrag: AN KK 258, fol. 148r, ed. GUIFFREY, Inventaires, Bd. 1, 1894, S. 247 , Nr. 943; LEBEUF, Recueil, Bd. 2, 1738, S. 259; BARROIS 1830, S. 90, Nr. 518; DOUËT D'ARCQ 1850, S. 231 und DELISLE, Le cabinet des manuscrits de la Bibliothèque Impériale, Bd. 3, 1881, S. 190, Nr. 246 (vgl. ebd., Bd. 1, 1868, S. 61) sowie DELISLE, Recherches sur la librairie de Charles V, Bd. 2, 1907, S. 263, Nr. 246. Vgl. bspw. VAUGHAN 1962, S. 198 und MEISS, French Painting in the Time of Jean de Berry: The Late Forteenth Century, Bd. 2, 1967, S. 372, Anm. 175. Siehe Anhang - Katalog/Jahreslisten, Nr. 1335. Ein Exemplar heute in der Bibliothèque Nationale de France, BNF ms.fr. 1023 (siehe auch Les plus belles pages manuscrites de l'histoire de France [Ausstellungskatalog], 1993, S. 42-45). Siehe auch oben S. 52, Anm. 72.

154 Angabe bei GUIFFREY, Inventaires, Bd. 1, 1894, S. 247, Nr. 943 nach SG ms. 841, Nr. 1109. Die Angabe zum Wert nach DELISLE, Le cabinet des manuscrits de la Bibliothèque Impériale, Bd. 3, 1881, S. 190, Nr. 246: 3 1. 15 s. (nach BARROIS 1830, S. 90, Nr. 518 waren es 60 s.p.).

155 Christine de Pisan, Les Sept Psaumes allégorisés, ed. RANNS, 1965. - Inventareintrag: AN KK 258, fol. 158v, ed. GUIFFREY, Inventaires, Bd. 1, 1894, S. 260, Nr. 977 (mit zusätzlichem Verweis auf das Inventar von 1416, SG ms. 841, Nr. 1124); LEBEUF, Recueil, Bd. 2, 1738, S. 260f.; DELISLE, Le cabinet des manuscrits de la Bibliothèque Impériale, Bd. 3, 1881, S. 181f., Nr. 129 (vgl. ebd., Bd. 1, 1868, S. 61); DELISLE, Recherches sur la librairie de Charles V, Bd. 2, 1907, S. 245, Nr. 129, und notiert unter der Nr. 203 bei BARROIS 1830 (Bibliothek des Lord Ashburnham). Ein zeitgenössisches Exemplar wurde von der Bibliothèque Nationale de France 1895 erworben, heute geführt als n.a.fr. 4792. 
Ereignisse der Zeit Karls VI. Ung Livre des Faiz d'armes et de chevalerie wurde dem Herzog 1413 geschenkt ${ }^{156}$. 1414, also nach den CabochiensUnruhen, bekam Berry ung livre qui est intitulé: le Livre de la paix ${ }^{157}$. Es ist nicht zu ermitteln gewesen, was Christine im Einzelfall dafür als Gegengaben erhalten hat. Möglicherweise ist der gobelet d'or, den Isabeau de Bavière 1405 verschenkte, ein entsprechendes Präsent für Christine gewesen ${ }^{158}$.

Christine de Pisans besondere Stellung liegt nicht nur darin begründet, daß sie eine Frau war, auch nicht nur darin, daß sie als Frau »selbständig « arbeitete und nicht formal-institutionell eingebunden war wie die vielen Goldschmiede oder die Brüder Limburg als Hofpersonal oder -lieferanten der Fürsten (und auch nicht auf eine einigermaßen existenzsichernde Grundlage zurückgreifen konnte wie Monstrelet oder Deschamps), sondern daß sie darüber hinaus mit ihren Themen Anliegen vertrat, hinter denen sie offensichtlich mit ihrer Überzeugung stand. Ihre schriftstellerische Tätigkeit ist deshalb nicht nur als ein Reflex auf existentiell notwendige fürstliche Zuwendungen zu sehen. Zeitbezug und das Vertreten eines persönlichen Standpunktes sind kennzeichnend für ihr Werk. Deshalb sind die adligen Adressaten ihrer Gaben nicht einzig als potentieller Quell ihres Wohlergehens zu sehen, sondern als mit Bedacht ausgewählte Empfänger von Christines Appellen, weise und gerecht zu sein und für den Frieden im Königreich zu sorgen. Der Herzog von Berry schien ihr der geeignete Mann für die Rolle eines einsichtigen Vermittlers gewesen zu sein: die Schenkdaten 1410 bis 1414 fallen mit dem Höhepunkt der Aus-

Hinweise nach DELISLE, Recherches sur la librairie de Charles V, Bd. 2, 1907, S. 301, Anm. 129. Der Wert wurde mit 5 l. bestimmt; Angabe bei GuIFFREY, Inventaires, Bd. 1, 1894, S. 260 , Nr. 977 nach SG ms. 841, Nr. 1124. Zum Wert siehe auch DELISLE, Le cabinet des manuscrits de la Bibliothèque Impériale, Bd. 3, 1881, S. 171: „Les prix qui terminent la plupart des articles se rapportent aux évaluations qui furent faites en 1416 à la requête des exécuteurs testamentaires du duc de Berry; ces prix sont toujours exprimés en monnaie tournois «. Siehe Anhang - Katalog/Jahreslisten, Nr. 1467.

156 Christine de Pisan, The book of Fayttes of Armes and of Chyualrye, ed. BAYLES, 1937. Inventareintrag: AN KK 258, fol. 163r, ed. GUIFFREY, Inventaires, Bd. 1, 1894, S. 270 , Nr. 1004; DELISLE, Le cabinet des manuscrits de la Bibliothèque Impériale, Bd. 3, 1881, S. 193, Nr. 289 (vgl. ebd., Bd. 1, 1868, S. 61), und DELISLE, Recherches sur la librairie de Charles V, Bd. 2, 1907, S. 269, Nr. 289. Siehe Anhang - Katalog/Jahreslisten, Nr. 1561.

157 Christine de Pisan, Le Livre de la Paix, ed. WILLARD, 1958, vgl. SOLENTE 1924, S. 266 mit Anm. 4). Inventareintrag: AN KK 258, fol. 214r, ed. GUIFFREY, Inventaires, Bd. 1, 1894, S. 332, Nr. 1239 (mit zusätzlichem Verweis auf das Inventar von 1416 SG ms. 841, Nr. 1139), DELISLE, Le cabinet des manuscrits de la Bibliothèque Impériale, Bd. 3, 1881, S. 193, Nr. 288 (vgl. ebd., Bd. 1, 1868, S. 61) und DelisLE, Recherches sur la librairie de Charles V, Bd. 2, 1907, S. 269, Nr. 288. Auch hier ist nur ein Wert von 5 l. notiert (zum Wert siehe oben). Siehe Anhang - Katalog/Jahreslisten, Nr. 1613.

158 Im relativ bescheidenen Wert von 4 1. 2 s.p., siehe AN KK 43, fol. 109v. Siehe Anhang - Katalog/Jahreslisten, Nr. 1342. 
einandersetzungen zwischen Bourguignons und Armagnacs zusammen und der »Livre de la paix « legt beredtes Zeugnis ab von Christines Anliegen ${ }^{159}$.

Aber es war nicht nur Christine de Pisan, die zum neuen Jahr Handschriften verschenkte. Zweimal ist dokumentiert, daß sogar ein Herzog unter den Schenkern war: Philipp der Kühne überreichte einer namentlich nicht bekannten Person 1402 einen traité aristotélicien de la propriété des choses tout nuef escript et ystorié160 im Wert von immerhin 400 écus d'or, belegt in einer Rechnung seines Generalrentmeisters Jean Chousat ${ }^{161}$. 1404 hatten die Sekretäre des Herzogs von Berry, Erard Moriset, Jean de Cande, Michel le Beuf und Pierre de Gynes, diesem eine Handschrift gleichen Inhalts (?) zugeeignet 162.1414 schließlich war es der Bruder der Königin, Ludwig der Bärtige ${ }^{163}$, der Johann von Berry ung petit livre du Trésor maistre Jehan de Mehun, escript en françoys rimé, de grosse lettre de fourme, bien ystorié et enluminé 164 verehrte, den berühmten Rosenroman, von dem oben schon kurz die Rede war ${ }^{165}$. Alle anderen Schenker befanden sich in Umkehrung der

$159 \mathrm{Vgl}$. AUTRAND, Jean de Berry, 2000, S. 418-459.

160 Zur Enzyklopädie des Bartholomäus Anglicus neuerdings MEYER 2000.

161 Siehe ACO B 1526, fol. 298, vgl. DAVID 1945, S. 46. Siehe Anhang - Katalog/ Jahreslisten, Nr. 1205.

162 Inventareintrag: AN KK 258, fol. 147r, ed. GUIFFREY, Inventaires, Bd. 1, 1894, S. 246, Nr. 939, LEBEUF, Recueil, Bd. 2, 1738, S. 258f., DELISLE, Le cabinet des manuscrits de la Bibliothèque Impériale, Bd. 3, 1881, S. 183, Nr. 145 (vgl. ebd., Bd. 1, 1868, S. 60) und DELISLE, Recherches sur la librairie de Charles V, Bd. 2, 1907, S. 247, Nr. 145. Siehe Anhang - Katalog/Jahreslisten, Nr. 1283. Ein Exemplar dieser Hs. befindet sich heute in Madrid, Museo Lázaro Galdiano, ms. 505 nach MEISs, French Painting in the Time of Jean de Berry: The Late Forteenth Century, Bd. 2, 1967, S. 317f.; Berry ist diese Hs. allerdings nicht eindeutig zuzuordnen.

163 STRAUB 1965, S. 169 allg. zum Geschenkaustausch zwischen Ludwig und Katharina d'Alençon, dem Herzog von Berry und dem Dauphin.

164 Inventareintrag: AN KK 258, fol. 214r, ed. DOUËT D'ARCQ 1850, S. 164, Nr. 65, DELISLE, Le cabinet des manuscrits de la Bibliothèque Impériale, Bd. 3, 1881, S. 183, Nr. 148, GUIFFREY, Inventaires, Bd. 1, 1894, S. 332, Nr. 1238 (mit zusätzlichem Verweis auf das Inventar von 1416 SG ms. 841, Nr. 528, vgl. GUIFFREY, Inventaires, Bd. 1, 1894, S. CXLIX und ebd., Anm. 2 sowie ebd., S. CLXXV, Nr. 61) und DELISLE, Recherches sur la librairie de Charles V, Bd. 2, 1907, S. 247, Nr. 148. Siehe Anhang - Katalog/Jahreslisten, Nr. 1643. Zum Verbleib dieses Buches GuIFFREY, Inventaires, Bd. 1, 1894, S. CLXXIIf,, Nr. 51, nach DELISLE, Recherches sur la librairie de Charles V, Bd. 2, 1907, S. 247, Nr. 148 verkauft an den Grafen von Armagnac, wahrscheinlich heute BNF ms.fr. 568 (weitere Exemplare aus dem Besitz Berrys BNF ms.fr. 380, siehe MEISs, French Painting in the Time of Jean de Berry: The Late Forteenth Century, Bd. 2, 1967, S. 313 und BNF ms.fr. 12595, siehe MEISS, French Painting in the Time of Jean de Berry: The Late Forteenth Century, Bd. 2, 1967, S. 315).

165 Siehe oben S. 97 mit Anm. 122, dort Angabe der Ed. - STRAUB 1961, S. 13f., Anm. 1: "Wie eine Parteinahme im Rosenromanstreit mutet es an, daß er dem greisen Herzog von Berry zum Neujahrstag 1414 das 'Livre du trésor/ des umstrittenen Jehan de Meung schenkte." Berry schenkte Ludwig im selben Jahr ung hanap d'or couvert im Wert von 2131.5 s. 8 d.t., siehe AN KK 250, fol. 45r, ed. GUIFFREY, Inventaires, Bd. 2, 1896, S. 333. 
sonst zum größten Teil zu machenden Beobachtung unterhalb der fürstlichen Hierarchieebene ${ }^{166}$.

Von Gilles Malet, dem garde de la librairie des Louvre, erhielt Philipp der Kühne 1396 die belles croniques de france ${ }^{167}$, von seinem Kanzler Jean Canard, leider ist der Schenktermin nicht bekannt ${ }^{168}$, ung bon Messel, à l'usaige de Paris [...] couvert d'une chemise de drap de Damas blanc semée de marguerites $P$. et $M$. de brodure d'or et six boutons de perle ${ }^{169}$, von Dino Rapondi aus Lucca, seinem finanziellen Sachwalter, 1400 un très bel livre de l'Istoire de Titulavieux enluminé de lettres d'or et hystoires d'imaiges en

STRAUB 1965, S. 169 mit Anm. 620 irtt, wenn er unter Bezugnahme auf GuiffreY, Inventaires, Bd. 1, 1894, S. 332, Nr. 1238 diese Handschrift mit dem ,Livre du Trésorı des Brunetto Latini identifiziert.

166 Wobei festgestellt werden kann, daß sich hierarchische Einflüsse in der schriftlichen Fixierung der étrennes in den archivalischen Beständen weder in einer entspr. Sortierung noch in der Wortwahl niederschlagen.

167 Siehe VERNET, André: Art. 》Chroniques (Grandes) de France«, in: LexMA, Bd. 2, 1983, Sp. 2034f., hier Sp. 2034, Abschn. 3. - ACO B 1508, fol. 109r nennt das Gegengeschenk für Gilles Malet, vaisselle d'argent im Wert von $200 \mathrm{fl}$. (vgl. BNF, Coll. de Bourgogne, vol. LIII, fol. 166, PETIT 1888, S. 553), verzeichnet aber auch das Geschenk Malets. Möglicherweise ist dies die im Inventar der Margarete von Flandern von 1405 verzeichnete Chronik, ACO B 302, fol. 34 und wieder fol. 35, siehe WINTER 1985, S. 166f., Nr. 175 und S. 171, Nr. 196. Möglicherweise aber auch identisch mit der nach dem Inventoire des livres Roumans de feu monseigneur Philippe le Hardi, que maistre Richart le Conte, son barbier, a euz en garde à Paris 1404 mit den ergänzenden Hinweisen fermans à deux fermouers d'argent, armoiez aux armes de feu mon dict seignour bei BARROIS 1830, S. 105, Nr. 605 verzeichneten Chronik, vgl. ACO B 301, fol. 36, siehe WINTER 1985, S. 130, Nr. 33. Vgl. HuGHES 1978, die in ihrem Aufsatz die Sammlungen Philipps des Kühnen und Margaretes von Flandern behandelt. Siehe dort zum vorliegenden Geschenk Malets v.a. S. 168f., Nr. 10 und S. 185, Nr. 5 in der Rubrik »VIII. Historical texts. (A) Europe and England.« Vgl. Prost 1891, S. 337f., 338, Nr. 5, DoutrePONT 1906, S. $37 f$., Nr. 75 sowie PEIGNOT, Catalogue d'une partie des livres composant la bibliothèque des ducs de Bourgogne, 1841, S. 41f., 73, 75. WINTER 1985, S. 59, 167 datiert m.E. falsch auf 1397. Möglicherweise heute BNF ms.fr. 2608. Siehe Anhang - Katalog/Jahreslisten, Nr. 699.

168 Als Datierungsgrundlage dient Patrick M. de WINTER der Beginn des Episkopats Canards 1392, der trotz seiner Bischofswürde weiterhin hauptsächlich in Paris residierte, um seinen Aufgaben als Kanzler Burgunds gerecht zu werden, so daß dieses Meßbuch zwischen 1393 und 1403 verschenkt worden sein könnte, vgl. WINTER 1985, S. 122, Nr. 2 mit weiteren Nachweisen zum Schicksal dieser Hs.

169 Inventareintrag: ACO B 301, fol. 17, ed. BARROIS 1830, S. 107, Nr. 623 (hier nach dem Inventoire des livres Roumans de feu monseigneur Philippe le Hardi, que maistre Richart le Conte, son barbier, a euz en garde à Paris 1404, PEIGNOT, Catalogue d'une partie des livres composant la bibliothèque des ducs de Bourgogne, 1841, S. 52f. (vgl. ebd., S. 29f., Anm. 2), DEHAISNES, Documents et extraits, Bd. 2, 1886, S. 839, DOUTREPONT 1906, S. 2 f., Nr. 2 (nach dem Inventar Philipps des Guten von 1420, fol. 31v-32r.) und WINTER 1985, S. 122, Nr. 2 (ebd., S. 59: »Le missel principal utilisé pour l'autel de la chapelle ducale [...]«). Zu Stoffeinbänden der Zeit neuerdings COILLY 1999. 
plusieurs et divers lieux, et aussi couvert bien richement ${ }^{170}$, und von dessen Bruder Giacomo 1403 "De mulieribus claris «171 des Giovanni Boccaccio. Es war Martin Gouge, der Berry 1411 »Des Cas des nobles hommes et femmes«, translaté de latin en françoys par Laurens de Premierfait, schenkte172.

Jacques Courau ${ }^{173}$, trésorier général des Herzogs, vermehrte Berrys Sammlung 1402 um einen grant livre de Valerius Maximus, historié et escript de lettre de court; et au commencement du second fueillet a escript: urbis Romae; couvert de veluiau vermeil, garni de IIII fermouers d'argent dorez, esmaillez aux armes de monseigneur ${ }^{174}$. Guillaume de Boisratier, der spätere

170 Titus Livius, Ab urbe condita. - Inventareintrag: ACO B 301, fol. 36 (vgl. DAVID 1947, S. 111 mit Anm. 3), ed. PEIGNOT, Catalogue d'une partie des livres composant la bibliothèque des ducs de Bourgogne, 1841, S. 28f., DEHAISNES, Documents et extraits, Bd. 2, 1886, S. 778, DOUTREPONT 1906, S. 33-35, Nr. 70 und WINTER 1985, S. 131, Nr. 35. Vgl. HuGHES 1978, S. 166, S. 169, Nr. 12 und S. 186, Nr. 6 in der Rubrik »IX. Classical works. « WYLIE, History of England under Henry the Fourth, Bd. 2,1, 1896, S. 259, Anm. 2 notiert das Geschenk einer »History of Titus Livius, illuminated with gold letters, envoyé en bonnes estrennes« durch Philipp den Kühnen für 1398, was offensichtlich ein Irrtum ist. ACO B 1517, fol. 128r nennt das Gegengeschenk Philipps, 500 fr. d'or. Heute befindet sich ein Exemplar, das ursprgl. Berry gehört hat (siehe GUIFFREY, Inventaires, Bd. 1, 1894, S. CLXIX, Nr. 40), in der BNF ms.fr. 263. Siehe Anhang - Katalog/Jahreslisten, Nr. 1020.

171 Inventareintrag: AN KK 258, fol. 162v, ed. LEBEUF, Recueil, Bd. 2, 1738, S. 259, DOUẼT D'ARCQ 1850, S. 152f., Nr. 21, GUIFFREY, Inventaires, Bd. 1, 1894, S. 265, Nr. 993 und DELISLE, Recherches sur la librairie de Charles V, Bd. 2, 1907, S. 256, Nr. 208, S. $333 \mathrm{f}$. Vgl. GuIfFreY, Inventaires, Bd. 1, 1894, S. CLXXVIf., Nr. 72 und ebd., S. CLXXIX, Nr. 3. Nach DELISLE, Recherches sur la librairie de Charles V, Bd. 2, 1907, S. 256, Nr. 208 verkauft an den Grafen von Armagnac und ebd., S. 256 mit Anm. 3 nicht mehr in der Bibliothèque Nationale de France, vgl. ebd., S. 307f., Anm. 208: MEISs, French Painting in the Time of Jean de Berry: The Late Forteenth Century, Bd. 2, 1967, S. 310 weist diese Hs. der Genfer Stadt- und Universitätsbibliothek zu, dort enthalten als ms.fr. 190. Siehe Anhang Katalog/Jahreslisten, Nr. 1539. Siehe GATHERCOLE 1968. - Heute BNF ms.fr. 12420. Vgl. PEIGNOT, Catalogue d'une partie des livres composant la bibliothèque des ducs de Bourgogne, 1841, S. 31 , HughES 1978, S. 169, Nr. 13 und S. 181 , Nr. 8 in der Rubrik »VI. Didactic works « (datiert auf 1401), vgl. MEISs, French Painting in the Time of Jean de Berry: The Late Forteenth Century, Bd. 2, 1967, S. 4f., 47, 252, 355, 362, Anm. 7. Siehe ThомaS 1979, S. 70. Siehe Anhang - Katalog/Jahreslisten, Nr. 1277. Von Philipp erhielt Jacques im Gegenzug im selben Jahr 300 1. d'or nach HuGHES 1978, S. 169, Nr. 13 und S. 181, Nr. 8. - Auch der Herzog von Berry besaß ein Exemplar (»Le livre des femmes nobles et renommées «), heute BNF ms.fr. 598, vgl. GUIFFREY, Inventaires, Bd. 1, 1894, S. CLXXVIf., Nr. 72 - Übers. und komm. von Irene ERFEN: Giovanni Boccaccio, De claris mulieribus, 1995, grundlegend BUETTNER 1996.

$172 \mathrm{Zu}$ den frz. Übers. der Werke Boccaccios im 15. Jh. BozzoLo 1973.

173 Nicht »Jean de Coureau« wie BARROIS 1830, S. 89, Nr. 510, und nicht 1401.

174 Wohl die „Facta et dicta memorabilia« des Valerius Maximus. - Inventareintrag: AN KK 258, fol. 139v, ed. LEBEUF, Recueil, Bd. 2, 1738, S. 259 (fälschlich datiert auf 1407 a.St.), BARROIS 1830, S. 89, Nr. 510 (enthalten in der Rubrik »Inventoire et prisée des Livres de Jean duc de Berry, Frère du roi Charles quint; en 1416 « nach einem »original sur Vélin [...] conservé dans la Bibliothèque de Saint-Geneviève, à Paris« - versehen hat BARROIS seine Angaben mit dem irreführenden Hinweis auf S. 89: „Voila un temoignage que les estreines ne se donnent pas a cause du premier jour de l'année, qui lors ne commençoit qu'à 
Erzbischof von Bourges und Kanzler Berrys, schenkte diesem 1404 un livre de Sidrac, escript en françoys, de lettre de fourme, et au commancement du second fueillet a escript: cellui vint; couvert de cuir vermeil empraint, à deux fermouers d'argent dorez, esmaillez aux armes de monseigneur, et les tixuz de soye noir; et par dessus ledit livre a une chemise de drap de soye noir, doublé de sendal vermeil175.

Von Martin Gouge, dem Vorgänger Boisratiers als Kanzler, und wie Boisratier nicht der einzige, von dem Johann von Berry mehrfach über die Jahre hinweg (Neujahrs-)Geschenke erhalten hat, stammten als Gabe zum jour de l'an 1408 die Komödien des Terenz ${ }^{176}$. Gérard du Puy schließlich, der Bischof von Saint-Flour, verehrte dem Herzog 1406 un petit livre en latin, qui s'adrece à monseigneur le Duc, compilé par Aymeri, abbé de Moisac177, des Lamentations de la mort du roy Charlemaigne, escript de lettre de fourme et historié en plusieurs lieux; et au commancement du second fueillet a escript: partibus; couvert de cuir vermeil houssié, et par dessus une chemise de drap de damas noir, doublé de tierceline vermeil, garni de deux fermouers d'or, ou

Pasques« nach einer »note de Le Laboureur« [hier das Inventar nach den Rechnungen »de l'execution de prince a. 1416《 - LELABOUREUR, Histoire de Charles VI, 2 Bde., 1663, stand zur Überprüfung nicht zur Verfügung]), DELISLE, Le cabinet des manuscrits de la Bibliothèque Impériale, Bd. 3, 1881, S. 187, Nr. 206, GUIFFREY, Inventaires, Bd. 1, 1894, S. 236f., Nr. 911 und DELISLE, Recherches sur la librairie de Charles V, Bd. 2, 1907, S. 256, Nr. 206. Heute nicht BNF ms.fr. 263 (siehe oben S. 107, Anm. 170) wie BARROIS 1830, S. 89, Nr. 510, sondern BNF ms.fr. 282, vgl. GUIFFREY, Inventaires, Bd. 1, 1894, S. 236, Anm. 4; vgl. MEISS, French Painting in the Time of Jean de Berry: The Late Forteenth Century, Bd. 2, 1967, S. 313. Siehe Anhang - Katalog/Jahreslisten, Nr. 1148.

175 Ed. STEINER 1994. - Inventareintrag: AN KK 258, fol. 146v-147r, ed. LEBEUF, Recueil, Bd. 2, 1738, S. 259, PEIGNOT, Catalogue d'une partie des livres composant la bibliothèque des ducs de Bourgogne, 1841, S. 61, DELISLE, Le cabinet des manuscrits de la Bibliothèque Impériale, Bd. 3, 1881, S. 183, Nr. 149, GUIFFREY, Inventaires, Bd. 1, 1894, S. 245f., Nr. 938 und DELISLE, Recherches sur la librairie de Charles V, Bd. 2, 1907, S. 248, Nr. 149. Zweifelsfrei nach ebd., S. 248, Nr. 149 die Hs. Nr. 11113 der Königlichen Bibliothek Brüssel, bestätigend MEISS, French Painting in the Time of Jean de Berry: The Late Forteenth Century, Bd. 2, 1967, S. 49 mit Anm. 170, S. 372. Siehe Anhang Katalog/Jahreslisten, Nr. 1285. - Die Spur der Mappamonde de toute la Terre sainte, die Berry von Boisratier 1405 erhalten hatte, siehe ebd., Nr. 1339, hat sich verloren, ebenso diejenige des 1404 verschenkten messel, siehe ebd., Nr. 1284, wie auch des pontiffical von 1403, siehe ebd., Nr. 1219.

176 Siehe LEBEUF, Recueil, Bd. 2, 1738, S. 260, DELISLE, Recherches sur la librairie de Charles V, Bd. 2, 1907, S. 265, Nr. 261, GuIFFREY, Inventaires, Bd. 1, 1894, S. 257, Nr. 969 und ebd., Bd. 2, 1896, S. 277, Nr. 1122. Siehe Anhang - Katalog/Jahreslisten, Nr. 1446. Siehe MEISs, French Painting in the Time of Jean de Berry: The Late Forteenth Century, Bd. 2, 1967, S. 315f.: heute BNF ms.lat. 7907A (vgl. GuIFFREY, Inventaires, Bd. 1, 1894, S. CLXXIII, Nr. 55).

177 Es handelt sich um den gelehrten Abt Aymeric de Peyrac (1377-1406) von St-Pierre de Moissac. 
il a, en l'un, un ours, et en l'autre, en cigne, tenant chascun en escuçon ésmaillié aux armes de monseigneur ${ }^{178}$.

Die Spuren der Handschriften, die Gérard du Puy Berry geschenkt hat, wie der livre en latin, de Meditationibus editis ab Anselmo, Cantuariensi archiepiscopo ${ }^{179}$ und der livre de Sidrac ${ }^{180}$, haben sich verloren.

Auch Simon Aligret, Arzt des Herzogs, trat mehrfach als Schenker in Erscheinung, bezeichnenderweise überwiegend mit medizinwissenschaftlichheilkundlichen Handschriften. Leider ist weder der livre d'Abvinscene ${ }^{181}$, noch ein Exemplar des berühmten livre de Medicine, appelé Galien ${ }^{182}$, noch der Livre de medecine, qui traicte de la vertu des herbes et des bestes ${ }^{183}$, noch der Psaultier glosé184 in eindeutiger Zuordnung, also mit spezifischem Bezug auf den damit einst beschenkten Herzog, erhalten. Dies gilt auch für die Handschriften, die Berry von Arnoul Belin ${ }^{185}$, dem trésorier der Sainte-Chapelle

178 Inventareintrag: AN KK 258, fol. 149v, ed. LEBEUF, Recueil, Bd. 2, 1738, S. 259f; BARROIS 1830, S. 91, Nr. 523; DOUËT D'ARCQ 1850, S. 158, Nr. 46; DELISLE, Le cabinet des manuscrits de la Bibliothèque Impériale, Bd. 3, 1881, S. 190, Nr. 245; GUIFFREY, Inventaires, Bd. 1, 1894, S. 249f., Nr. 950 und DELISLE, Recherches sur la librairie de Charles V, Bd. 2, 1907, S. 262f., Nr. 245, vgl. Delisle, Le cabinet des manuscrits de la Bibliothèque Impériale, Bd. 1, 1868, S. 59, 60. Siehe Anhang - Katalog/Jahreslisten, Nr. 1360. Zwei Exemplare dieser Hs. in Paris, BNF ms.lat. 5944 bzw. 5946, allerdings ist keines dem Herzog von Berry zuzuordnen, vgl. DELISLE, Le cabinet des manuscrits de la Bibliothèque Impériale, Bd. 3, 1881, S. 190, Nr. 245.

179 1410, siehe Anhang - Katalog/Jahreslisten, Nr. 1469, Es handelt sich wohl um die 》Orationes sive Meditationes« des Anselm von Canterbury.

180 1404, siehe Anhang - Katalog/Jahreslisten, Nr. 1285. Siehe auch oben S. 108, Anm. 175.

181 1404, siehe Anhang - Katalog/Jahreslisten, Nr. 1328. Zu Avicenna siehe zunächst ENDRESS, Gerhard, LAUER, Hans H.: Art. »Avicenna«, in: LexMA, Bd. 1, 1980, Sp. 12981300. Avicenna, span.-lat. für Abū'Alī al-Husain ibn 'Abdallā Ibn Sīnā, war nach ENDRESS ein islam. Universalgelehrter von philosophischer, medizinischer und musiktheoretischer Bedeutung an den iranischen Fürstenhöfen Ende des 10./Anfang des 11. Jh.s. Bei dem livre d'Abvinscene wird es sich um ein medizinisches Werk gehandelt haben, möglicherweise um das nach LAUER im Mittelalter sehr beliebte Traktat »Qānūn fĩ t-tibb« (Satzung bzw. Kanon der Medizin). Eine umfassende Darstellung Avicennas Leben, Wirken und Nachwirken gibt STROHMAIER 1999, siehe hier u.a. zu dem Kanon der Medizin S. 109ff., zur Verbreitung des Kanon S. 125-127. Die Diss. SCHNEIDER 1990, eine Übersetzung und Bearbeitung von Auszügen aus dem »Canon medicinae«, behandelt den Kanon S. 16f. und dessen Überlieferung und Nachwirkung im lateinischen Mittelalter S. 17-19. Wertvoll die Arbeit SCHNIPPERGES 1987 mit zahlr. Abb., Anm. und weiterführenden Hinweisen.

182 1405, siehe Anhang - Katalog/Jahreslisten, Nr. 1353. Bei dem Galien handelt es sich um die Sammlung der Schriften Galens (bzw. Galenus'), eines griechisch-römischen Arztes, der von 129 bis 199 n.Chr. lebte und Leibarzt des römischen Kaisers Mark Aurel war.

183 1413, siehe ebd., Nr. 1609.

184 1415, siehe ebd., Nr. 1687.

185 Siehe ebd., Nr. 1656 (1415) und 1688 (1416). 
von Bourges, Gieffroi (Geoffroy) Robin ${ }^{186}$, Pierre Trousseau ${ }^{187}$ und Ugo de Robertis de Tripoli 188, Patriarch von Alexandria, zum neuen Jahr bekam.

Außer Johann von Berry ist es nur noch Ludwig von Orléans gewesen, der zum neuen Jahr Handschriften verehrt bekam.

1400 bekam Ludwig von Aumary d'Orgemont, seinem Kanzler, un grant livre en latin, couvert d'une grant chemise de drap de soye, ouvré de plusieurs soyes, à deux fermoriers d'or, esmaillé de nos armes, sur deux tixus de soye noire ${ }^{189} .1402$ übergab ihm der Augustiner Jacques Legrand ${ }^{190}$, Universitätslehrer und Schriftsteller (»Sermones«, "Compendium philosophiae«, "De arte memorandi« etc.), der anfangs als Ankläger der vorgeblichen Verschwendung durch die Königin und Ludwig auftrat, nach 1407 aber zu den Armagnacs wechselte und im Auftrag der Herzöge Berry, Bourbon und Orléans 1412 sogar nach England reiste, um den englischen König um Hilfe zu bitten, eine Übersetzung seiner »Archilogesophie«, des »Archiloge Sophie« in Nachfolge des "Sophologium«, einer moralisch-wissenschaftlichen Kompilation, das die Liebe zur Weisheit und zu den Wissenschaften sowie die Liebe zu den theologischen Tugenden anmahnte und das Wissen um alle Reiche der Welt vermitteln wollte und heute noch in vier Exemplaren erhalten ist ${ }^{191}$.

186 1406, siehe Anhang - Katalog/Jahreslisten, Nr. 1361.

187 1405, BNF ms.lat. 17173, fol. 228, Nr. 35, vgl. DELISLE, Le cabinet des manuscrits de la Bibliothèque Impériale, Bd. 3, 1881, S. 174, Nr. 36, GUIFFREY, Inventaires, Bd. 2, 1896, S. 313 und Delisle, Recherches sur la librairie de Charles V, Bd. 2, 1907, S. 229, Nr. 36. Siehe Anhang - Katalog/Jahreslisten, Nr. 1351. Wahrscheinlich ist dies eine falsche Datierung oder es handelt sich um einen Schenker gleichen Namens, obwohl auch GUIFFREY, Inventaires, Bd. 2, 1896, S. 313, Anm. 3 Trousseau als Erzdiakon von Paris identifiziert. Pierre Trousseau, eine zu den sog. Marmousets zu zählende Persönlichkeit, war 1390 mit Ferri Cassinel und Jean d'Estouteville beteiligt an der Bereinigung der korrupten Verwaltung des Herzogs von Berry im Languedoc, gest. 1393.

1881404 , siehe Anhang - Katalog/Jahreslisten, Nr. 1330.

189 Siehe LABORDE, Les Ducs de Bourgogne, Bd. 3, 1851, S. 201 f., Nr. 5946 nach „Catalogue de M. de Courcelles« ohne weitere Angaben. Vgl. DELISLE, Le cabinet des manuscrits de la Bibliothèque Impériale, Bd. 1, 1868, S. 99. Siehe Anhang - Katalog/Jahreslisten, Nr. 1019. Verbleibangaben sind nach diesen Hinweisen nicht möglich.

190 Jacobus Magnus, siehe LEFÈVRE, Sylvie: Art. "Jacques Legrand«, in: Dictionnaire des lettres françaises, 1996, S. 773f.; siehe RAHNER, Erwin: Art. "19. J. Magni«, in: LexMA, Bd. 5, 1991, Sp. 259 - vgl. KRYNEN 1981, pass.

191 Eine Hs. ist vorhanden in Paris: BNF ms.fr. 143, Ed. Jacques Legrand: Archiloge Sophie, hg. von BELTRAN, 1986 (vgl. WYLIE, History of England under Henry the Fourth, Bd. 2,2, 1898, S. 66, Anm. 1). Vgl. PARIS, Les Manuscrits français, Bd. 1, 1836, S. 284 und DELISLE, Le cabinet des manuscrits de la Bibliothèque Impériale, Bd. 1, 1868, S. 99. Grundlegend »De Jacobi Magni« von Alfred CoVILLE 1889 (in lat. Sprache; hier S. 1-37 zur Biographie, 38-49 zum Werk, 50-84 zum "Sophologium«, 62ff. dann zur »Archilogesophie«). Siehe Anhang - Katalog/Jahreslisten, Nr. 1149. 